\title{
ESPAÑA Y LA CRUZADA MÉDICA CONTRA \\ LA MASTURBACIÓN (1800-1900). ELEMENTOS PARA UNA GENEALOGÍA
}

por

\section{FRANCISCO VÁZQUEZ GARCÍA \\ José BENITO SEOANE CEGARRA \\ Universidad de Cádiz}

RESUMEN: En este trabajo, se trata de explicar la patologización del onanismo en la España del siglo XIX. Con este objetivo se adopta la perspectiva de los estudios sobre la gubernamentalidad liberal. La cruzada médica contra la masturbación se emplaza en la encrucijada de dos trayectorias. En primer lugar, la constitución de la familia burguesa, escindida de la esfera laboral. En segundo lugar, la formación de un tipo de sujeto adaptado a ese nuevo espacio doméstico. En la pugna por monopolizar este proceso, se localiza, dentro del contexto decimonónico español, el conflicto entre medicina, religión y.pedagogía.

Palabras Clave: Sexuality. Masturbation. Family. Medicine. Liberalism. Governmentality. Spain, nineteenth century.

ABSTRACT: This paper explains the «medicalisation» of onanism in nineteenth-century Spain. We take studies on liberal governmentality as a methodological paradigm. The medical campaign against masturbation is placed at the crossroads of two strands. First, we find the rise of the bourgeois family considered as a private field. Second, we see a mode of subjectivity adapted in accordance with this new domestic space. We analyze, in the context of nineteenth-century Spain, the conflict between Medicine, Education and the Church to control this process.

KEY WORDS: Sexuality. Masturbation. Family. Medicine. Liberalism. Governmentality. Spain, nineteenth century.

Han transcurrido ya varias décadas desde que los historiadores dejaron de considerar el fenómeno de la "cruzada médica antimasturbatoria» desplegada en Occidente a partir de mediados del siglo XVIII como un episodio más o 
menos anecdótico, una «curiosidad» añadida al devenir de nuestras costumbres sexuales ${ }^{1}$.

La descripción de este acontecimiento ha sido objeto de numerosos estudios referidos a áreas geográficas muy diferentes. El problema surge a la hora de acordar una interpretación sobre el asunto. Desde los años 60, se han multiplicado los intentos de explicar este singular proceso: ¿por qué, aproximadamente a partir de 1750 , la masturbación no sólo fue considerada por la moral sexual como un pecado sino también como un hábito enfermizo, generador de patologías sin término?

La historia social, la historia de las mentalidades, la historia de las ideas, han ofrecido al respecto múltiples interpretaciones. Se ha puesto en relación la represión victoriana del sexo y los intereses de la naciente burguesía con la nueva campaña sanitaria ${ }^{2}$; se ha sugerido que ésta respondía a un aumento real de las prácticas masturbatorias avalando esta tesis con referencias a las fluctuaciones demográficas (edad tardía del matrimonio, reducidas tasas de ilegitimidad y de nacimientos prenupciales) ${ }^{3}$, al auge de los internados escolares ${ }^{4}$, o a los nuevos bríos y obsesiones generados por el individualismo y la urbanización ${ }^{5}$. Se ha querido dar cuenta de la cruzada emprendida por higienistas y pedagogos articulándola con otros macroprocesos: los avances del racionalis$\mathrm{mo}^{6}$, la secularización de la moral sexual, la creciente preocupación por la in-

\footnotetext{
${ }_{1}^{1}$ Los primeros textos sobre historia de las costumbres sexuales parecen haber concedido una escasa importancia a este asunto. FUCHS, Eduard: Historia Ilustrada de la Moral Sexual, Madrid, Alianza Editorial, 1996 [ed. original publicada entre 1909 y 1912], 3 vols., no lo menciona, en contraste con cientos de páginas dedicadas al fenómeno de la prostitución. BLOCH, Ivan: Sexual Life in England. Past and Present, Royston, Oracle, 1996, dedica una página al tema (p. 464).

2 VAN UsSel, Jan: Histoire de la Répression Sexuelle, Paris, Robert Laffont, 1972; Lejeune, Philippe: «Le 'dangereux supplément'. Lecture d'un aveu de Rousseau», Annales ESC (Paris), n ${ }^{\circ} 29$ (1974), pp. 1005-1032; ARON, Jean Paul y KeMPF, Robert: «Le Pénis et la démoralisation de l'Occident», en La Bourgeoisie, le Sexe et lHonneur, Bruxelles, Ed. Complexe, 1984, pp. 159-200.

3 Flandrin, Jean Louis: La Moral Sexual en Occidente, Barcelona, Juan Granica, 1984, pp. 330-334.

4 CORBIN, Alain y Perrot, Michelle: "Entre bastidores», en AriÈs, Philippe y DubY, Georges (dir.): Historia de la Vida Privada, 4. De la Revolución Francesa a la Primera Guerra Mundial, Madrid, Taurus, 1989, p. 459; CARON, Jean Claude: «La segunda enseñanza en Francia y en Europa desde finales del siglo XVIII hasta finales del siglo XIX: colegios religiosos e institutos», en LEVI, Giovanni y SCHMITT, Jean Claude: Historia de los Jóvenes. II. La Edad Contemporánea, Madrid, Taurus, 1996, p. 217.

s SHORTER, Edward: Naissance da la Famille Moderne, Paris, Seuil, 1977, pp. 123-128; BOUCÉ, Paul G.: «Les jeux inderdits de l'imaginaire: onanisme et culpabilisation sexuelle au XVIII siècle», en CÉARD, Jean (comp.): La Folie et le Corps, Paris, Ed. de l'ENS, 1985, p. 242: LAQueUR, Thomas: «El mal social, el vicio solitario y servir el té», en FeHER, M., NADDAR, R. y TAZI, N. (eds.): Fragmentos para una bistoria del cuerpo bumano, vol. III, Madrid, Taurus, 1992, pp. 91-131.

6 Stengers, Jean y VAN NeCK, Anne: Histoire d'une Grande Peur: la masturbation, Bruxelles, Ed. de l'Université de Bruxelles, 1984, pp. 112-113.
}

Hispania, LXIV/3, núm. 218 (2004) 835-868 
fancia y la adolescencia ${ }^{7}$, o los intereses de la profesión médica por colonizar nuevos ámbitos de intervención ${ }^{8}$.

\section{SUGERENCIAS DE MÉTODO}

El examen pormenorizado de cada uno de estos argumentos es una tarea que excede los límites de este trabajo ${ }^{9}$. Sí se pueden señalar algunas cosas. En primer lugar, el razonamiento que conecta directamente la obsesión productivista de la burguesía industrial naciente con la represión generalizada del sexo parece desacreditado desde hace mucho tiempo, y no sólo por parte de historiadores más o menos foucaultianos ${ }^{10}$. En segundo lugar, no está clara la conexión causal entre un posible aumento de las prácticas onanistas y la aparición del discurso médico condenatorio. ¿Por qué no siguió imperando como había hecho hasta entonces el planteamiento teológico-moral ${ }^{11}$ ? Por último, la referencia a «intereses profesionales» tampoco proporciona un explanans convincente. Para que los higienistas del siglo XIX tuvieran unos intereses determinados en promover la campaña, era necesario que se forjara una identidad profesional y que existiera por tanto una demanda social de tales profesionales con unas competencias específicas ${ }^{12}$.

Consideramos que, con objeto de esquivar estas dificultades y si se quiere rebasar el plano puramente descriptivo, el marco más adecuado para afrontar el problema no es el que proporciona la historia social, de las ideas o de las mentalidades, sino el ámbito de una historia o genealogía de las «técnicas de gobierno», entendida en términos foucaultianos ${ }^{13}$. Las técnicas de gobierno son modos de acción (maneras de gestionar el tiempo, el espacio, los cuerpos individuales y colectivos) que pretenden orientar, dirigir o disuadir la acción de los otros. Estas técnicas pueden organizarse en actos discursivos (consejos, reglamentos, órdenes, sugerencias, amenazas, etc.) pero también en representaciones o en dispositivos materiales (artefactos, ordenamientos espaciales y temporales). La implantación

7 STONE, Lawrence: The Family, Sex and Marriage in England (1500-1800), London, Weidenfeld and Nicholson, 1979, pp. 515-516.

8 COMforT, Alfred: Los Médicos Fabricantes de Angustia, Barcelona, Tusquets, 1977, pp. 83-130.

9 Una revisión crítica de las principales hipótesis explicativas se encuentra en TARCZYLO, Théodore: Sexe et Liberté au Siècle des Lumières, Paris, Presses de la Renaissance, 1983, pp. 140-157.

10 Foucault, Michel: Les Anormaux. Cours au Collège de France. 1974-1975, Paris, École des Hautes Études en Sciences Sociales-Gallimard-Le Seuil, 1999, pp. 39-40 y 221-222; STONE, Lawrence: The Family, op. cit., pp. 515-516; TARCZYLO, Théodore: Sexe et Liberté, op. cit., pp. 152-157; Stengers, Jean y VAN NECK, Anne: Histoire d'une Grande Peur, op. cit., pp. 107-112.

11 TARCZYLO, Théodore: Sexe et Liberté, op. cit., pp. 145-152.

12 Una crítica a este uso ingenuo del concepto de «interés» se encuentra en BOURDIEU, Pierre: «El interés del sociólogo», en Cosas Dichas, Barcelona, Gedisa, 1993, pp. 108-113.

13 GORDON, Colin: "Governmental Rationality: an Introduction», en BurCHELL, G., GORDON, C. and MILLER, P. (eds.): The Foucault Effect. Studies in Governmentality, London, Harvester Wheatsheaf, 1991, pp. 1-48.

Hispania, LXIV/3, núm. 218 (2004) 835-868 
de estas técnicas implica la introducción de nuevos objetos y tipos de sujeto en el ámbito del discurso y de la acción. Así, este conjunto de prácticas discursivas y no discursivas que introducen algo como objeto de discurso o de acción es lo que Foucault designó con el nombre de «problematizaciones».

Pues bien, desde esta perspectiva, el conjunto de recomendaciones, mandatos, artefactos, dispositivos arquitectónicos e imágenes que componen la campaña sanitaria contra la masturbación infantil y adolescente puede ser afrontado como una tecnología de gobierno que da lugar a un nuevo tipo de "problematización". Nuevos objetos y tipos de sujeto entran desde entonces en el campo del saber: el «joven masturbador», la «ninfómana», el «higienista», «el padre negligente», «las malas compañías iniciadoras» (domésticos, compañeros de internado, etc..), «las epidemias masturbatorias en los colegios», las «pérdidas seminales involuntarias", las complejas relaciones causales entre la masturbación y otras patologías (desde la espermatorrea hasta la locura), los nexos entre desvirilización y masturbación, entre onanismo y despoblación, entre el «vicio solitario» y la vida insana de las grandes ciudades, la edad de entronización en el «funesto hábito", etc..

En general, se puede decir que las estrategias habilitadas por la medicina y por la pedagogía desde 1750 para perseguir la masturbación componen una tecnología «liberal» de gobierno. Se trataba de promover a la familia y a la institución escolar como agentes de vigilancia e intervención en relación con la conducta sexual de los jóvenes. Frente al intervencionismo estatal en el campo de los comportamientos sexuales, defendido en el siglo XVIII por los teóricos de la Medizinischen Polize ${ }^{14}$, se pretendía que fueran las propias instancias de la sociedad civil las que actuaran regulando autónomamente esta esfera. La gubernamentalidad liberal no significa «menos gobierno» de las conductas, sino «menos gobierno estatal» de las mismas, y su acción se apoya en la autonomía reguladora de la propia sociedad civil ${ }^{15}$.

La medicina se introduce aquí siempre a título de asesor, no como delegado de un Estado clínico autoritario ${ }^{16}$. Por eso, las actuaciones directas del facultativo (remedios químicos, ortopedia, cirugía) se reservan exclusivamente para los casos extremos, cuando el gobierno familiar o escolar fracasan. Técnica «liberal» porque respeta, en cualquier caso, las fronteras que escinden lo privado de lo público; pero también porque descansa en la capacidad de los individuos, de

\footnotetext{
${ }^{14}$ Sobre el disciplinamiento de la sexualidad infantil y adolescente en los tratados de policía médica de Johan Peter Franck y Franz Anton Mai a fines del siglo XVIII, ver RoseN, George: «El destino del concepto de policía médica», en De la Policía Médica a la Medicina Social, México, Siglo XXI, 1985, p. 171 .

is Ver DEAN, Mitchell: «Liberal Government and Authoritarianism», Economy and Society, vol. 31 (2002), $\mathrm{n}^{\circ} 1$, pp. 38-40.

16 FOUCAUlT, Michel: Les Anormaux, op. cit., pp. 234-36. La relación entre cruzada médica antimasturbatoria y formación de un Estado Terapéutico autoritario aparece en SZASZ, Thomas: Sex: Facts, Frauds and Follies, Oxford, Blackwell, 1980, pp. 16-24.
}

Hispania, LXIV/3, núm. 218 (2004) 835-868 
las familias y de las instituciones para autogobernarse, desconfiando de toda intrusión por parte de la autoridad pública.

La tecnología dirigida específicamente al gobierno de la sexualidad de los jóvenes y que toma como blanco el problema de la masturbación, forma parte de lo que desde Foucault se viene designando con el nombre de "biopolítica»" ${ }^{17}$. Se trata de un modo de ejercer el poder, constituido paulatinamente en el área occidental a partir del siglo XVIII, que tiene como objeto, no propiamente a sujetos jurídicos sino a "poblaciones». Su modo de proceder, a diferencia del poder característico del Absolutismo, no es negativo (por resta o extracción de fuerzas, como en las ejecuciones, confiscaciones o destierros) sino positivo (se trata de intensificar la fuerza y calidad biológica de las poblaciones).

El onanismo es representado pues como un factor que debilita los organismos individuales, una conducta sexual que además es improductiva desde el punto de vista demográfico. Si se trata de gobernar para vigorizar el cuerpo social e incrementar la población - verdadera «riqueza» de las naciones para los reformadores ilustrados y para buena parte de sus sucesores liberales- se entiende perfectamente el pánico suscitado por la masturbación de niños y adolescentes ${ }^{18}$.

Sin embargo, aunque los conceptos foucaultianos de "técnica de gobierno» y de «biopolítica» nos permiten analizar el modus operandi de la estrategia sanitaria contra la masturbación, no parecen proporcionarnos una explicación satisfactoria de su génesis y perseverancia a lo largo de décadas. ¿Por qué esa angustia y esa profusión verbal de higienistas, pedagogos, filósofos y teólogos en relación precisamente con el "vicio solitario»?; ¿por qué la campaña se mantuvo en su intensidad hasta la segunda mitad del siglo XIX?

Sin duda es correcto hablar de estrategia para referirse a la «cruzada sanitaria» contra la masturbación. Pero no debe pensarse que estamos ante un programa conscientemente calculado y deliberado. Estamos más bien ante el resultado, no previsto, del encuentro entre dos series de procesos. Por una parte, una coyuntura histórica objetiva: la constitución de la familia burguesa como ámbito privado, separado de la esfera de la producción y apoyado a su vez en una rígida separación de los roles de género, una separación que se fundamentaba, además, en criterios biológicos ${ }^{19}$. Y el nexo entre las luchas contra la masturbación en el siglo XVIII y la exigencia de separación rígida entre los géneros

17 Foucault, Michel: Histoire de la Sexualité, 1. La Volonté de Savoir, Paris, Gallimard, 1976, pp. 177-198.

${ }^{18}$ La conexión explícita entre campaña antimasturbatoria y biopolítica aparece en FOUCAULT, Michel: «Il Faut Défendre la Société». Cours au Collège de France. 1976, Paris, École des Hautes Études en Sciences Sociales-Gallimard-Le Seuil, 1997, pp. 224-225.

19 Laqueur, Thomas: La Fabrique du Sexe. Essai sur le corps et le genre en Occident, Paris, Gallimard, 1992. 
ha sido señalado por Pierre Bourdieu al indicar que esas luchas pretenden derrocar el debilitamiento, el afeminamiento producido por el onanismo ${ }^{20}$.

Por otra parte, estaría la constitución paralela de un determinado sistema de necesidades, de disposiciones subjetivas - lo que Bourdieu denomina el habitus ${ }^{21}$ - ajustado al nuevo espacio familiar. La actitud calculadora, el comedimiento, la respetabilidad, la preocupación por la higiene personal, la voluntad de forjarse «un carácter», la autodisciplina, serían, entre muchos otros, los elementos de este habitus característico del varón perteneciente a las clases medias y profesionales urbanas, conformado por contraste con la representación de las disposiciones aristocráticas (libertinaje, afeminamiento, gasto improductivo, ocio, avidez de lujos) y de las clases populares (imprevisión, salvajismo, promiscuidad, suciedad, descuido físico y moral). No hay que olvidar que el modelado de las identidades sociales se apoya, en buena medida, en una manipulación simbólica del cuerpo, convertido en un libro donde deben leerse los signos de la pertenencia de clase y de género ${ }^{22}$.

En torno a este prototipo de familia y a esta matriz de disposiciones, se configuró un nuevo mercado de servicios materiales y simbólicos. Entre los distintos productores que intervinieron en ese mercado (higienistas, pedagogos, directores de conciencia, novelistas, arquitectos, artistas, etc..) se efectuó una verdadera lucha simbólica para monopolizar, entre otras cosas, la definición legítima de la salud corporal y espiritual ${ }^{23}$. Aquí se inserta la estrategia sanitaria de lucha contra la masturbación: esta conducta concentraba todas las obsesiones del momento (pérdida de autocontrol, disolución del carácter y de la identidad, desfallecimiento de la virilidad, debilitamiento físico y mental, sexualidad improductiva y sin futuro). El onanismo era la expresión del desorden en el gobierno de uno mismo y de la imposibilidad de reproducir la propia unidad familiar, la ruina de todo aquello sobre lo que descansaba el emergente babitus de clase media.

Se tienen pues tres niveles de análisis. En primer lugar, el espacio variable de estrategias que componen una peculiar tecnología de gobierno cuyo blanco principal es la masturbación de niños y adolecentes varones, y sólo secundariamente el onanismo femenino ${ }^{24}$. En segundo lugar, el espacio de relaciones

20 BOURDIEU, Pierre: «La retórica del cientifismo: contribución a un análisis del efecto Montesquieu", en ¿Qué significa bablar?, Madrid, Akal, 1985, p. 155.

${ }^{21}$ Dos de las exposiciones más asequibles de este concepto se encuentran en BOURDIEU, Pierre: Cosas Dichas, op. cit., pp. 22-26, y Razones Prácticas, Barcelona, Anagrama, 1997, pp. 18-21.

22 BOURDieu, Pierre: Esquisse d'une Théorie de la Pratique, Paris, Seuil, 2000, p. 294.

23 BourdieU, Pierre: "La disolución de lo religioso", en Cosas Dichas, op. cit., pp. 102-107. Sobre la lucha entre pedagogos y médicos por la definición legítima de los usos corporales, ver BouRdieu, Pierre: Questions de Sociologie, Paris, Minuit, 1984, pp. 181-182.

${ }^{24}$ Sobre este papel secundario ya en Tissot, ver TARCZYLO, Théodore: Sexe et Liberté, op. cit., p. 127, y sobre la conexión del onanismo femenino con el problema de la ninfomanía, ver VÁzQUEZ

Hispania, LXIV/3, núm. 218 (2004) 835-868 
- de conflicto, alianza, complementariedad, indiferencia, etc...- en el que distintos cuerpos profesionales - principalmente pedagogos, médicos y eclesiásticos - pugnan por establecer el discurso y las prácticas legítimas acerca de la sexualidad infantil y juvenil. Por último, habría que reconstruir el campo de posiciones y tomas de posición adoptadas por los higienistas en relación con el problema del onanismo analizando sus variaciones a partir de distintos indicadores: edad, procedencia social y geográfica, emplazamiento institucional, prestigio científico reconocido, cargos públicos desempeñados, etc... En este trabajo, nos limitaremos a explorar los dos primeros espacios señalados.

\section{LAS PECULIARIDADES DEL CASO ESPAÑOL. UNA POSIBLE PERIODIZACIÓN}

Pero no basta con indicar las coordenadas generales en las que se emplazan los nuevos pánicos y las nuevas estrategias suscitadas por el «vicio solitario». Hay que inscribir el proceso en el contexto español concreto, con sus propias peculiaridades. De forma comparativa y sumaria, se pueden precisar algunas de ellas.

En primer lugar, la recepción española de la campaña médica antionanista fue relativamente tardía en comparación con lo acontecido en otros países de Europa Occidental (Francia, Alemania, Gran Bretaña, Holanda, Italia) ${ }^{25}$. Después de varios intentos frustrados por la censura de libros, el Traité de lOnanis$m e$ de S. A. Tissot - texto fundacional de la campaña - fue por fin vertido al castellano y autorizada su publicación en $1807^{26}$. Este retraso, empero, estaba paliado en parte debido a la difusión de las tesis del médico ginebrino a través de algunos tratados de conservación de la salud traducidos con anterioridad. Por otro lado, en contraste con lo sucedido en otras naciones europeas, no hay constancia de que ningún médico español dedicara una monografía al asunto.

García, Francisco y Moreno Mengíbar, Andrés: Sexo y Razón. Una Genealogía de la Moral Sexual en España (siglos XVI-XX), Madrid, Akal, 1997, pp. 426-435.

${ }_{25}$ Una referencia casi exhaustiva a las ediciones y traducciones de Tissot en TarCZYLo, Théodore: Sexe et Liberté, op. cit., pp. 291-296.

${ }^{26}$ Sobre la recepción de esta obra en España, son imprescindibles los trabajos de PERDIGUero GIL, Enrique: Los Tratados de Medicina Doméstica en la España de la Ilustración, Alicante, Publicaciones de la Universidad de Alicante, 1991; Perdiguero GIL, Enrique: «L'Onanisme de Simón André Tissot en la España del siglo XIX», en VALerA, M. y LÓPEZ FernánDeZ, C. (eds.): Actas del V Congreso de la Sociedad Española de Historia de las Ciencias y de las Técnicas, Murcia, D.M.-P.P.U., 1991, pp. 1165-1182; PERDIGUero GIL, Enrique: «La imposible publicación de la versión castellana de L'Onanisme de S. A. Tissot en la España de la Ilustración", en BujosA, F. et Al.: Actas del IX Congreso Nacional de Historia de la Medicina, Zaragoza, Prensas Universitarias de Zaragoza, 1991, pp. 1073-1081; Perdiguero GIL, Enrique y GonZÁlez De Pablo, Ángel: «Los valores morales de la higiene. El concepto de onanismo como enfermedad según Tissot y su tardía introducción en España», Dynamis. Acta Hispánica ad Medicinae Scientiarum Historian Illustrandam (Granada), $\mathrm{n}^{\circ} 10$ (1990), pp. 131-162. 
No faltaron en cambio amplios desarrollos recogidos en tratados de higiene, así como artículos de prensa especializada, reseñas, comentarios y traducciones de obras extranjeras. Hemos consultado una muestra de 73 entradas de este material, sin incluir en él las referencias a los peligros sanitarios del onanismo recogidas en manuales de ginecología, pediatría y escritos de tono divulgativo. El intervalo cronológico abarca desde 1807, fecha de la traducción autorizada del texto de Tissot, hasta 1912, cuando se edita en Madrid el Curso de Higiene Individual y Social de R. Forns, autor considerado como «epígono de la historia de la higiene española ochocentista» ${ }^{27}$. En este conjunto, se incluye una veintena de tratados y monografías médicas traducidas a partir de otros idiomas, mayoritariamente del francés.

¿Cómo puede explicarse este retraso en la recepción española? Michel Foucault sugiere la hipótesis de que la emergencia y el temprano éxito de la campaña médica antionanista en el mundo protestante (el texto del galeno suizo fue inmediatamente vertido al francés, inglés y alemán) se debió a la ausencia, en estos países, de una extensa y antigua red de seminarios e internados para jóvenes así como a la inexistencia de procedimientos de confesión y dirección de conciencia. El locuaz y plástico discurso sanitario y pedagógico sobre la masturbación, surgido en los países protestantes, coincidiría cronológicamente con una época en la que las técnicas de confesión y guía de almas, en el campo católico, estaban sufriendo una importante transformación.

Autores tan influyentes como Alfonso Liguori ejemplifican la tendencia, creciente a partir del siglo XVIII, a buscar tácticas verbales de interrogación que, sin renunciar al principio de integridad en la confesión, evitaran las descripciones demasiado reveladoras e ilustrativas del pecado carnal, enseñando a los jóvenes lo que no debían aprender. Es como si, al menos desde esta época, la gran profusión discursiva en torno a la carne y a sus concupiscencias, característica de la pastoral postridentina, hubiera iniciado un reflujo dejando su lugar a fórmulas más discretas y silenciosas, como los mudos ordenamientos y disciplinas establecidos en los seminarios y colegios donde se formaba la élite de la juventud católica ${ }^{28}$.

Aunque las versiones italiana (Venecia, 1784) y española (Madrid, 1807, si bien el primer intento fallido data de 1785) de la obra de Tissot son relativamente tardías, y es cierto que la producción de monografías propias sobre el tema es casi inexistente en estos países, no deja de ser significativo el hecho de que, en el caso español, la oposición frontal a la traducción del libro de Tissot viniese de las instituciones médicas (Academia Médica-Matritense, Tribunal Real del Protomedicato), contando en cambio, en algún caso, con el placet de la autoridad religiosa (el Vicario Eclesiástico de Madrid). Precisamente, los facul-

${ }_{27}$ GrANJEL, Luis S.: «El niño en la historia de la medicina», Studia Pedagogica, nº 6 (1980), pp. $73-74$

${ }^{28}$ FOUCAUlt, Michel: Les Anormaux, op. cit., pp. 218-219.

Hispania, LXIV/3, núm. 218 (2004) 835-868 
tativos que se opusieron a la traslación castellana de L'Onanisme argumentaban que la viveza de las descripciones del ginebrino eran una invitación al vicio juvenil ${ }^{29}$. ¿No parecen estos hechos contradecir la hipótesis de Foucault?

Sin renunciar a la sugestiva conjetura del pensador francés, que requeriría mayores exploraciones, es probable también que el lento despegue de la campaña antionanista en países como España tuviera relación directa con la persistencia durante décadas de un discurso higiénico menos secularizado e independizado de la moral religiosa que en otros países de Occidente. Esto se relacionaría también con el limitado y tardío desarrollo, en España, de unas élites urbanas netamente diferenciadas por su estilo de vida, incluyendo los usos sociales del cuerpo, de las maneras difundidas entre las clases populares.

Entre el «populismo» —encarnado por el «majismo» a fines del siglo XVIII-, más o menos afectado, de una parte importante de la aristocracia y la exaltación de la fuerza viril exteriorizada propia de las clases subalternas, quedaba poco espacio para el ethos del honnête bomme, caracterizado por el comedimiento, el pudor, la moderación, la urbanidad y la higiene corporal, entre otras $\cos ^{30}{ }^{30}$. La figura ridiculizada del «afrancesado» concentrará, en buena medida, el desprecio suscitado por formas que se consideraban «extranjerizantes». Esta precariedad social de la demanda en relación con las prácticas y representaciones elaboradas por la higiene está también en la raíz del retraso.

Por último, en relación con los análisis de Foucault sobre el problema, se puede señalar otra singularidad del caso español. El filósofo francés señala en efecto que la "cruzada antimasturbatoria» se encauzaba, fundamentalmente, en el ámbito doméstico ${ }^{31}$. Se trataba, ante todo, de impedir que las malas compañías de «domésticos dudosos» o la negligencia de los padres fomentaran el vicio solitario entre los niños. Esta estrategia coincidía además con la tendencia, en buena parte de los países occidentales desde fines del siglo XVIII, al desarrollo de los grandes establecimientos de enseñanza destinados a las clases favorecidas. Frente a la titubeante educación familiar, se hacía valer la eficacia y rigor de la educación escolar. La masturbación era por tanto más fácil de controlar en los internados - mediante minuciosos dispositivos antionanistas, como los estipulados en el Philantropinum alemán de Basedow a fines del siglo XVIII ${ }^{32}$, o los programados por el Dr. Demeaux en $1848^{33}$ - que en el hogar.

\footnotetext{
29 Perdiguero Gil, Enrique: Los Tratados de Medicina Doméstica, op. cit., pp. 143-146.

30 Sobre el nexo existente entre el estilo de vida de las clases medias y el discurso higienista, ver LABISCH, Alfred: «Doctors, Workers and the Scientific Cosmology of the Industrial World: the social construction of health and the Homo Hygienicus», Journal of Contemporary History, vol. 20 (1985), pp. 599-615.

31 FouCAUlt, Michel: Les Anormaux, op. cit., pp. 241-242.

32 TARCZYLO, Théodore: Sexe et Liberté, op. cit., pp. 133-138; STENGERS, Jean y VAN NeCK, Anne, Histoire d'une grande peur, op. cit., pp. 100-104.

33 ARON, Jean Paul y KEMPF, Robert: «Le Pénis et la démoralisation de l'Occident», op. cit., pp. 203-220. El proyecto de Demeaux se tradujo parcialmente en Dr. DemEAUX: «Nuevo método
} 
Este cuadro no funciona desde luego en el caso español. Lo que aquí se encuentra de forma abrumadoramente mayoritaria es un discurso que hace valer la superioridad de la educación familiar - debidamente asesorada por la medicina - sobre la instrucción escolar. Las asechanzas del onanismo se localizan principalmente, según los higienistas españoles, en colegios e internados; bien por la intervención de compañeros «avezados» que inician a los más inocentes o por los descuidos de los preceptores. No en vano hablarán de «vicio escolar» para referirse a la masturbación. En esta defensa de la familia frente a la escuela vienen a coincidir los higienistas más conservadores y católicos - que asocian la primacía del medio escolar con los avances del laicismo estatal - y los liberales más anticlericales - que vinculan la práctica masturbatoria con la gazmoñería represiva e hipócrita característica de los internados religiosos. El discurso a favor de la escuela en relación con la campaña antionanista sólo se encuentra en España en el campo de los pedagogos. Estos insistirán en que el «vicio escolar» se origina, en realidad, en la esfera doméstica. La importancia de esta rivalidad entre medicina y pedagogía hace que le concedamos amplio espacio en este trabajo.

Una vez señaladas algunas de las peculiaridades de la «cruzada antimasturbatoria» en el caso español, parece conveniente delimitar las coordenadas cronológicas de nuestra investigación. Los testimonios que atribuyen al desperdicio de semen la producción de enfermedades pueden rastrearse a lo largo de siglos. Desde los médicos de la España medieval y renacentista hasta los moralistas y psiquiatras de la era franquista, se puede encontrar establecida la conexión causal entre patología y frecuencia de pérdidas seminales. La campaña médica antimasturbatoria no consiste sin embargo en establecer esta atribución, sino en situarla dentro de una "problematización específica» del comportamiento sexual de la infancia y la juventud.

La mencionada campaña se inscribe en el interior de un discurso higiénico, imperante entre mediados del siglo XVIII y finales del siglo XIX, centrado en el problema de los fluidos corporales y de su correcta economía. Por eso, el problema del onanismo era afrontado con el mismo estilo de razonamiento utilizado en relación con la cuestión de la lactancia mercenaria ${ }^{34}$.

La pérdida o la retención excesivas del semen o de la leche eran vistas como causas de innumerables patologías. La literatura higienista española, desde 1800 hasta las últimas décadas del siglo XIX, trataba el primer asunto ajustándose a un modelo cuantitativo que permitía representar la economía sexual humana. El uso de lo que se conocía como «instinto de propagación» implicaba un dispendio de energía que debía mantenerse dentro de ciertos límites si se

para evitar el onanismo y reprimir sus abusos», El Siglo Médico (Madrid), $\mathrm{n}^{\circ} 207,20$ diciembre de 1857.

34 Donzelot, Jacques: La Police des Familles, Paris, Éditions de Minuit, 1977, pp. 18-21; RICHTER, Siegfried: "Wet-Nursing, Onanism and the Breast in Eigteenth-Century Germany", Journal of the History of Sexuality, vol. 7 (1996), pp. 1-22.

Hispania, LXIV/3, núm. 218 (2004) 835-868 
quería preservar el equilibrio del organismo ${ }^{35}$. El estado patológico consistía en una disminución o aumento en relación con un gasto sexual moderado. Las nociones de "continencia excesiva» y de "incontinencia» (esta última se consideraba más común) designaban la causa de un variado repertorio de enfermedades que iban desde la esfera puramente física (impotencia, esterilidad, tabes dorsal, tuberculosis, ceguera, sífilis, etc..) hasta la mentả (pérdida de la razón, histeria, ninfomanía, etc.).

El paradigma de este discurso higienista era sin duda la masturbación, verdadera «enfermedad total» que, en el límite, podía figurar en el cuadro etiológico de cualquier patología ${ }^{36}$. En este marco conceptual, las conductas sexuales heterodoxas eran acogidas como manifestaciones de excesos cuyo símbolo era el funesto vicio del onanismo, pero no existía ninguna preocupación por catalogar las variedades existentes estableciendo una nosografía a partir de sus diferencias cualitativas.

A finales del siglo XIX, comenzó a difundirse en España el nuevo discurso psicopatológico sobre la sexualidad forjado por psiquiatras franceses, británicos y alemanes ${ }^{37}$. La masturbación infantil y adolescente siguió teniendo relevancia patológica, pero ya no ocupaba el lugar central y casi exclusivo de atención. Las nuevas teorías degeneracionistas y anatomoclínicas que vertebraban la psicopatología sexual convertían al onanismo de las primeras edades en un síntoma o en un factor etiológico de las «perversiones sexuales» — catalogadas minuciosamente por la nueva disciplina - pero desmantelaban su condición de «enfermedad total» al romper su separación respecto a otras desviaciones sexuales. $\mathrm{El}$ «vicio solitario» pasaba a un segundo plano de atención y comenzaba entonces una empresa de desmitificación en relación con las tesis de Tissot y de la higiene decimonónica.

En el caso español, los primeros indicios claros de este cambio se pueden observar en algunos testimonios médicos recogidos en la primera década del siglo $\mathrm{XX}$. El autor anónimo de la recensión de una tardía monografía sobre el onanismo señaló así la escasa novedad de un asunto ya tratado por Pouillet, Tissot, Lallemand, Mata y Yáñez, autores que fueron «señalando más o menos exageradamente los desastres que produce en el organismo tal modo de mancillar el cuerpon ${ }^{38}$.

35 NYE, Robert: «Sex difference and male homosexuality in French medical discourse, 18301930», Bulletin of the History of Medicine, vol. 63 (1989), $\mathrm{n}^{\circ}$ 1, p. 34; NYE, Robert (ed.): Sexuality, Oxford, Oxford U.P., 1999, p. 12.

${ }^{36}$ FOUCAUlt, Michel: Les Anormaux, op. cit., pp. 224-227. Este autor sitúa históricamente la «cruzada médica antimasturbatoria» entre el discurso contrarreformista sobre la concupiscencia carnal y el desarrollo de una psicopalogía sexual (Ibid., pp. 259-260).

37 Sobre la difusión del degeneracionismo en España, ver CAMPOS, Ricardo: «La Teoría de la degeneración y la profesionalización de la psiquiatría en España (1876-1920)», Asclepio (Madrid), vol. 51 (1999), n 1, pp. 185-203.

38 Revista de Ciencias Médicas, vol. 19 (1908), p. 223. La obra reseñada es Carbonell, Daniel: El Onanismo. Su prehistoria, su bistoria, sus causas y sus consecuencias, Caracas, 1907. 

boga:

En otro texto de esta época, se señala también que el asunto ya no está en

«Al llegar a este punto se nos aparece un problema que hemos de resolver con valentía; pues los aires modernos no soplan del lado adonde nos conduce nuestra firme convicción y el resultado de nuestra experiencia. Tal problema es el de evitar, prácticamente, que un joven el cual está cercano a la pubertad, y sobre el cual haya sospechas de onanismo, persista en $\tan$ feo vicio» 39 .

La «cruzada antimasturbatoria» se extinguía pues aunque, de modo fragmentario, a la manera de los restos de un naufragio o de la persistencia de residuos fósiles, algunos de sus argumentos (v.g. la conexión entre onanismo y ceguera) volverían ocasionalmente de la mano de los moralistas en la España del Nacionalcatolicismo.

\section{LA HIGIENE ESPAÑOLA Y LA CRUZADA ANTIMASTURBATORIA}

Los higienistas fueron unos de los agentes, junto a pedagogos y teólogosmoralistas, que participaron en la lucha por establecer un discurso y práctica legítimos respecto de la sexualidad infantil y juvenil. Durante el siglo XIX, la Higiene se había convertido en un ámbito de conocimiento científico, y había dejado de ser simplemente un calificativo físico. Representaba la rama preventiva de la medicina, la «clínica del hombre sano»: se trataba más de fortalecer el organismo que remediar las dolencias, de conservar la salud y "prolongar la vida” más que ejercer una terapéutica (por otra parte bastante ineficiente y desprestigiada en esta época en España).

La Higiene, desde mediados del siglo XIX, se convirtió en una herramienta de las técnicas de gobierno liberales, en conexión con un modelo de asistencia que buscaba mejorar las condiciones sanitarias de la población (cuyo valor productivo adquiriría gran importancia en la consolidación de los Estados nacionales). Bajo el lema "Gobernar es higienizar» ${ }^{40}$, los higienistas se aplicaron sobre los problemas sanitarios de las aglomeraciones urbanas y las crecientes amenazas al nuevo orden social por parte del naciente proletariado ${ }^{41}$. En su discurso ante la Sociedad Española de Higiene, Ángel Fernández Caro afirmaba así:

\footnotetext{
39 PIGA, Antonio: Higiene de la Pubertad, Toledo, Imp. De la Viuda e Hijos de Peláez, 1910, p. 15.

40 FERnÁNDez Caro, Ángel: Discurso de la Sesión Inaugural de la Sociedad Española de Higiene. Año Académico 1886-1887 (27 de noviembre de 1886), Madrid, Imp. E. Teodoro, 1886, p. 38.

41 Sobre los pioneros de la Higiene en Europa, ver RODRíGUEZ OCAÑA, Esteban: «Por la salud de las naciones. Higiene, Microbiología y Medicina Social», en Historia de la Ciencia y la Técnica, $\mathrm{n}^{\circ}$ 45, Madrid, Akal, 1992, pp. 8-26. Sobre la Higiene española, ver COMENGE y FERRER, Luis: La Medicina en el. siglo XIX, Barcelona, Hijos de Espasa, 1914; GranJEL, Mercedes: Felipe Monlau y la bigiene del siglo XIX, Salamanca, Universidad de Salamanca, 1983, pp. 33-60.
}

Hispania, LXIV/3, núm. 218 (2004) 835-868 
«Gran día será aquel en que los gobernantes se convenzan de que vicio, injusticia, abuso, pecado y transgresión higiénica son palabras sinónimas, quizá idénticas, y de que virtud, vicio y enfermedad son resultados inseparables. [Se lograría con ello] hacer inútil la policía y con ella las prisiones y los tribunales, cerrar los garitos y arruinar las casas de escándalo; dar al obrero, después del rudo trabajo del día, la paz y el bienestar de su casa; libertar a las mujeres del taller y devolverlas a sus maridos y a sus hijos [...], eso no se llama higiene, es economía política bien entendida, es patriotismo, es moral» 42 .

La Higiene española estuvo muy ligada generalmente a consideraciones morales que no abandonó siquiera en su etapa más positivista; en este sentido, en sus tratados, dirigidos a un público experto, se mantuvo la condena moral del onanismo, aunque sus autores criticaron, desde mediados del siglo XIX, las exageraciones de Tissot sobre las consecuencias físicas de la masturbación. Los posibles daños de tan extendido y accesible hábito se achacaron entonces a un tipo de onanismo «furioso» o, incluso, a las estrategias comerciales del charlatanismo médico (que aterrorizaba a sus víctimas para lograr vender sus remedios o provocaba, por el contrario, la incredulidad de muchos jóvenes respecto a los peligros de reiterar en su práctica). Para ello, se debía exponer al joven los peligros del hábito del onanismo, aunque el recurso al médico sólo se hacía en los casos más persistentes.

La mayor parte de las referencias a la sexualidad infantil y al onanismo en los tratados de higiene se encontraban en la sección dedicada a la bigiene privada. La nueva mentalidad etiológica ya había empezado a desconfiar, hacia mediados del siglo XIX, de los catálogos de enfermedades que, en una confusa relación causal, asociaban al onanismo una multitud de males sin dar clara cuenta de sus conexiones fisiológicas.

La Higiene era definida, respecto a la sexualidad, como «auxiliar a la moral» frente a los deseos inmoderados, recomendando la abstinencia de los placeres del amor durante la juventud y fuera del matrimonio. El «ojo experto» del médico debía desvelar la tendencia del onanista al disimulo y la tendencia al ocultamiento de su hábito (su aparente timidez, su afición a la soledad). Durante la primera infancia, las causas de este hábito podían ser orgánicas o irritativas (lombrices, falta de aseo o retención de la orina) y morales (como el mal ejemplo de padres o sirvientes); con la pubertad, con el tránsito de la familia a la escuela, cuando se hacía imposible prolongar la educación doméstica, aparecían nuevas amenazas: los compañeros de "precoces iniciaciones y perniciosas comunicaciones», la dificultad de una vigilancia intensiva en el espacio denso de la escuela, la falta de ejercicio corporal y la «excesiva educación intelectual» (que podían enervar y afeminar la hombre), o la actividad de la imaginación estimulada por la ociosidad, las novelas o la vida callejera y los espectáculos públicos. Los padres debían instruir a sus hijos sobre los peligros de este hábito

${ }^{42}$ Fernández Caro, Ángel: Discurso, op. cit. 
antes de entrar en los colegios, donde la masturbación se consideraba una enfermedad endémica. La prevención alcanzaba desde la disposición de los dormitorios, el ejercicio físico, las dietas, que excluían cualquier estimulante, o los anafrodisíacos. La terapéutica desarrolló distintos remedios mecánicos, químicos y quirúrgicos (estos últimos a partir del último cuarto del siglo XIX).

Durante la primera mitad del siglo XIX, la masturbación pasó gradualmente a ser definida dentro del alienismo (en conexión con la hipótesis de la locura masturbatoria), no propiamente como una enfermedad sino como un buen recurso, dada su extensión y a la vez su ocultamiento, para explicar toda una serie de patologías no bien conocidas. En la segunda mitad del siglo, primero los cirujanos y luego los pediatras se convirtieron en especialistas auxiliares, nuevos expertos en la prevención o curación del vicio solitario ${ }^{43}$. En el primer tratado pediátrico académico español, atribuido al catedrático Francisco Criado Aguilar, se afirmaba que el onanismo «no constituye una enfermedad, pero produce muchas y algunas terribles, por lo que merece un estudio especial»44.

En este tratado, en la primera sección (paidología), su autor señala entre las particularidades anatomo-fisiológicas del organismo infantil la «hiperasimilación», la debilidad y una «impresionabilidad exquișita» ${ }^{45}$. El onanismo aparece dentro de la sección segunda (paidopatía) dentro de las enfermedades del sistema nervioso en la infancia. El autor desconfiaba de los remedios farmacológicos, como los anafrodisíacos, aunque los consideraba convenientes en ciertos casos de «gran excitabilidad». En estos casos, establecía las dosificaciones diarias de medicamentos como el extracto alcohólico de lúpulo, bromuro de potasio, o "pincelaciones en el balano y en el clítoris con una solución de cocaína». Rechazaba los remedios quirúrgicos propuestos por otros autores extranjeros como «las pequeñas incisiones en el clítoris», la circuncisión o la «cauterización repetida de los labios de la vulva y de la cara interna de la vagina»; pero no despreciaba el uso de medios mecánicos, como el que proponía él mismo («un aparato construido ad hoc», un medio que confesaba no haber ensayado «todavía», pero que creía de gran eficacia) ${ }^{46}$.

Entre las causas del onanismo, se añadía entonces, por influencia del alienismo, «el temperamento nervioso muy pronunciado y la herencia neurótica en general». También entre los efectos señalaba, entre otros, la «depresión gene-

${ }_{43}$ Para conocer los precedentes de la Pediatría española y su desarrollo en Europa, ver GRANJEL, Luis S.: «El niño en la historia de la medicina», op. cit., pp. 53-69. En 1886 se creará en España la primera cátedra de «Enfermedades de la infancia», cuyos primeros catedráticos fueron Francisco Criado Aguilar y Andrés Martínez Vargas. Sobre el desarrollo de la pediatría en España, ver DE Miguel, Jesús: La amorosa dictadura, Barcelona, Anagrama, 1984.

${ }^{44}$ CRIADO Aguilar, Francisco: Tratado teórico-práctico de las enfermedades de los niños, Madrid, Imp. Asilo de Huérfanos del S. C. de Jesús, 1902, p. 855.

45 Ibid., p. 4.

${ }^{46}$ Ibid., p. 863.

Hispania, LXIV/3, núm. 218 (2004) 835-868 
ral», «un tinte de melancolía o tristeza» o «la enajenación mental y aún la imbecilidad" provocada por la frecuencia del hábito sobre los centros nerviosos ${ }^{47}$.

En el tratamiento higienista del onanismo, se entremezclaban variables como la edad, el género, la clase social y la raza, cuyas interrelaciones permitieron delimitar la sexualidad de la infancia de las élites urbanas. Respecto a la edad, se señalaba la especificidad de la infancia y las etapas de su desarrollo moral.

Pedro Felipe Monlau ${ }^{48}$, uno de los higienistas españoles más influyentes del siglo XIX, establecía que en la infancia (hasta los 7 años: «la edad del candor y la inocencia») lo que importaba era «ejercitar los sentidos externos, robustecer el cuerpo, dirigir sus instintos y educar sus sentimientos». A través del juego y del ejercicio al aire libre se intentaría prolongar lo más posible esa inocencia. Las «innumerables enfermedades» a que estaría sujeta esta edad las achacaba Monlau a las «transgresiones higiénicas o accidentes desgraciados, imputables a las nodrizas o a los padres» ${ }^{49}$.

La puericia o «segunda infancia» (de 7 a 15 años) era la edad del «primer despertar de los órganos genitales». El niño debía frecuentar el gimnasio (donde ejercer la práctica metódica de ejercicios activos) y la escuela (donde se iniciaba el cultivo de las facultades intelectuales, siempre bajo la «escrupulosa elección de maestros y maestras»). Los niños, además, debían empezar a dormir solos, «a lo más con otro niño de su edad o sexo, con tal de que esté sano y robusto", nunca con adultos ${ }^{50}$.

La juventud (de los 15 hasta los 25 años, o los 21 en la mujer) era la etapa donde Monlau situaba su análisis sobre el onanismo, y se caracterizaba por la aparición del «instinto de reproducción». Este instinto, que se manifestaba con

47 Ibid., p. 856.

${ }^{48}$ MonlaU, Pedro Felipe: Elementos de Higiene Privada, Barcelona, Lib. Moya y Plaza, 1846. Este texto de Monlau, recomendado en la Universidad española durante el curso 1846-1847, tuvo continuas ediciones a lo largo de los años 1857, 1864, 1870 y 1875. Monlau pertenecía a la "generación intermedia» entre «la especulación de la medicina romántica y la experimentación positivista». Estuvo muy vinculado a las doctrinas frenológicas y a las posturas poblacionistas antimalthusianas. Exiliado en Francia por sus ideas liberales, tendió progresivamente a ideas más conservadoras. Aunque sólo ocupó la cátedra de Higiene durante 1854 y 1868 , fue uno de los autores más influyentes en la Higiene española del siglo XIX, y sus obras sirvieron durante muchos años para la enseñanza de esta disciplina, desplazando a los anteriores tratados de Huffeland o Londe. Su posterior colaboración con los sectores políticos conservadores le llevaría a ocupar importantes puestos en la Sanidad española y a ser miembro de la Real Academia Española en 1858. Autor prolíico, aunque no de gran originalidad, tradujo a higienistas como Descuret (1842) o Feuchtersleben (1858) - tratados éstos de fuerte componente moral-, y desarrolló una importante labor higiénica divulgativa a través de revistas como El Monitor de la Salud o El Médico de las Familias. Ver GRANJeL, Mercedes: Monlau y la Higiene española del siglo XIX, op. cit., pp. 77-145, y, sobre las influencias europeas en la obra de Monlau, GONZÁLEZ DE PABLO, Ángel: «Sobre la configuración del modelo de pensamiento de la higiene actual: el caso español», Dynamis (Granada), n 15,1995 , pp. 283-285.

49 MONLAU, Pedro Felipe: Elementos de bigiene privada, op. cit., p. 475.

so Ibid. 
la primera menstruación o la secreción espermática, debía vigilarse para evitar su aparición prematura. Monlau señalaba que la facultad reproductiva dividía la vida humana en tres periodos: "En el primero no existe, en el segundo está activo, y en el tercero es nula»s1.

Otros higienistas españoles, como Rodríguez Guerra, Santero, Alcina o Ginés y Partagás, mantuvieron también esta postura, aunque adelantando el desarrollo de los hábitos onanistas algunos años, hacia la edad de la adolescencia o la pubertad. En general, dentro del higienismo español, la manifestación del onanismo, considerado como vicio o enfermedad (tanto semejaba valer, en ocasiones, un término como el otro), parecía hacerse más intenso y frecuente en la juventud y la adolescencia.

Sólo hacia finales del siglo XIX o a principios del siglo XX, especialmente en los tratados de pediatría española, se prestó atención al onanismo entre las enfermedades del sistema nervioso en la infancia desde muy tempranas edades, llegando a proponer remedios mecánicos y farmacológicos para los «casos de gran excitabilidad». Esta "plaga» era descrita por el pediatra español Francisco Criado como «un vicio casi exclusivo de la infancia», adelantándose así a la tendencia general en la tradición higienista que la situaba en la juventud o la adolescencia. Y esto se atribuía a la "falta de reflexión» en el niño, y, con ello, a la inexistencia de un «freno psíquico-moral» que controlara las pasiones ${ }^{52}$.

También abundaron pronto en la literatura higienista europea las denuncias sobre la aparición precoz de indicios del instinto genital ${ }^{53}$. Hacia finales del siglo XIX, el higienista francés J. B. Fonssagrives llegaba a dedicar un tratado específico a analizar y diferenciar el onanismo impúber, un tipo de onanismo producido por el contagio del ejemplo (la educación en común) y el influjo de la herencia (causas mórbidas), y frente al que proponía ampliar la vigilancia: «No es, por tanto, el lecho del joven, sino la misma cuna, lo que es preciso vigilar bien de cercan ${ }^{54}$.

En relación con la variable de la clase social, tomaba especial importancia la sección dedicada a la Higiene Pública, donde destacaba el problema de la infancia trabajadora, donde no preocupaba el onanismo sino la desestructuración familiar, la promiscua mezcla de sexos y edades en los talleres, el mal ejemplo o

\footnotetext{
sI lbid., p. 481.

52 CRIAdo Agullar, Francisco, Tratado teórico-práctico de las enfermedades de los niños, op. cit., p. 856.

53 LÉvy, Maurice: Tratado de Higiene Pública y Privada, Madrid, Ed. de la Galería Literaria, 1877, tomo I, p. 133. Esta obra del médico del Emperador e Inspector de Sanidad Militar, fue recomendada como libro de texto en la Facultades de Medicina españolas en 1853. Obra traducida por el médico José Núñez Crespo. La primera edición española es de 1846, dos años después de su original francesa.

${ }^{54}$ FONSSAGrives, Jean Baptiste: Tratado de la Higiene de la infancia, Madrid, Lib. El Cosmos, $1887,2^{a}$ ed., p. 456. La primera edición, de 1885, era una traducción de Manuel Flores y Pla.
} 
la seducción y explotación adulta sobre la infancia trabajadora, que producían su degradación moralss.

Cuando las agitaciones obreras impulsaron a los higienistas a interesarse por la condición moral de las clases obreras, se empezó a denunciar la «descuidada educación» del niño trabajador, la miseria moral de la familia proletaria o los funestos ejemplos que recibían en las fábricas (las conversaciones demasiado libres o la promiscuidad sexual), que podían producir en esos niños una temprana precocidad ${ }^{56}$.

Por el contrario, las clases elevadas se veían afectadas, en su sensibilidad e inteligencia, por los progresos de la civilización, por las enfermedades nerviosas y epidémicas que favorecían el ritmo y aglomeración de la vida urbana, su artificialidad, los ficticios apetitos que generaba una hipertrofiada imaginación que parecía no reconocer barreras naturales. Se denunciaba, en el fondo, el malestar que producían la creciente autocoacción y exigencia de control de los impulsos con el que las nacientes élites urbanas habían intentado constituir su cuerpo de clase. La percepción de continuas amenazas exteriores (como el incremento de las causas morbíficas y la "corrupción de las costumbres») debían mantener al individuo siempre alerta y fortalecer su voluntad, en una tarea de preservación que se presentaba casi heroica.

En la carta de un director de una escuela pública inglesa que recogía el médico inglés W. Acton, el primero se preguntaba:

«Ignoro si este vicio [el onanismo] está tan extendido entre los pueblos salvajes y en las clases obreras. Si no lo está, preciso será creer que una especie de estímulo artificial somete a las clases elevadas y a las sociedades civilizadas a una prueba que deben sufrir, y arrastra a su pérdida a los que no tienen fuerzas bastantes para resistir la tentación»\$7.

55 Monlau, Pedro Felipe: Elementos de Higiene Pública, Barcelona, Rivadeneyra, 1847, vol. II, pp. 545-548. Se reeditó en 1862 y 1871 . Sobre la higiene de los pobres en España, ver LóPEz PINERO, Joaquín y Otros: Medicina y Sociedad en la España del siglo XIX, Madrid, Sociedad de Estudios y Publicaciones, 1964, pp. 131-164, y GONZÁlEz Duro, Enrique: Historia de la locura en España, Madrid, Temas de Hoy, 1995, vol. 2, pp. 228-233.

56 Giné y PARTAGÁs, Juan: Curso Elemental de Higiene Privada y Pública, Barcelona, Imp. Narciso Ramírez y Cía., 1871-1872, tomo 4, p. 39. En 1866, Giné y Partagás, uno de los impulsores de la introducción y desarrollo de la medicina positivista, se convirtió en el primer catedrático de Higiene de la Facultad de Barcelona, puesto que ocupó hasta 1871. Su obra sirvió como libro de texto para el estudio de esta disciplina en la Facultad catalana. Ver DOMÉNECH, E. y CORBELLA, J.: «Las vertientes principales de la obra médica de Giné y Partagás», Asclepio (Madrid), vol. XXI (1987), pp. 173-178, y GRANJEL, Mercedes: Monlau y la Higiene española del siglo XIX, op. cit., pp. 71-73.

57 ACTON, William: Higiene trascendental de los órganos de la generación. Sus funciones y desórdenes, Barcelona, La Enciclopedia. Ed. Felipe N. Curriols, 1892, p. 43. Esta traducción de la obra del influyente médico inglés era una ampliación refundida a cargo del divulgador Amancio Peratoner. Existía una edición anterior de 1877 (Barcelona, Ed. José Codina). La primera edición inglesa es de 1857. 
La Higiene se convertía en un medio de vigorización y perfeccionamiento del organismo, en la alianza que desarrollaron las élites urbanas para conjurar lo que percibían como «degeneración del hombre», reorientando según sus intereses el proceso de la civilización, corrigiéndola «en sus desvaríos» ${ }^{58}$. Los pueblos «salvajes» y las clases obreras, excluidas de este progreso, establecían, por otro lado, sus afinidades. El onanismo era señalado como una de las causas de esta degeneración, aunque en todo este proceso las relaciones causa-efecto a menudo se invertían o resultaban confusas. Y todavía a finales del siglo XIX, el onanismo era situado por algunos autores «a la altura de la sífilis y el alcoholismo» respecto a las causas de la degeneración de la especie ${ }^{59}$.

Hubo, no obstante, críticas a esta percepción. El higienista francés M. Lévy afirmaba por ejemplo:

«Colocamos entre los medios preventivos el cultivo a la inteligencia, porque es absurdo acusar como se hace a la civilización del vicio del onanismo: iQué más segura garantía contra las inclinaciones vergonzosas que el desenvolvimiento de las más nobles facultades del hombre!»60.

Lévy respondía así a la descripción que hacía uno de los autores más influyentes de la cruzada antionanista en Europa, el médico francés C. F. Lallemand, que afirmaba que la masturbación no se había desarrollado apenas en la antigüedad y que «este vicio hipócrita parece pertenecer a las sociedades modernas, porque no exige cómplice ni aun virilidad completa, porque oculta sus maniobras y burla la vigilancia [...]; pasión solitaria y concentrada, arrastra a la mentira, al disimulo» ${ }^{6}$.

La variable del género fue otro condicionante importante a la hora de establecer preceptos higiénicos. A partir de la pubertad se establecía una marcada separación en las reglas higiénicas entre el hombre y la mujer. Progresivamente, como afirmaba el higienista francés Descuret, con el desarrollo de la edad, la mujer se ponía bajo la «influencia del sentimiento», mientras que el hombre se situaba bajo «la influencia de su cerebro». Esto explicaría que «las pasiones extremadas son todavía más delirantes en la mujer que en el hombre» ${ }^{62}$. Monlau también insistía en la mayor sensibilidad de la mujer, en la que predominaban las facultades afectivas, mientras que en el hombre dominaban las intelectuales ${ }^{63}$.

\footnotetext{
58 MONLaU, Pedro Felipe: Elementos de Higiene Privada, op. cit., p. 3.

59 FONSSAGRIVES, Jean Baptiste: Tratado de la bigiene de la infancia, op. cit., p. 453.

60 LÉvy, Maurice: Tratado de Higiene Pública y Privada, op. cit., p. 703.

${ }^{61}$ Ibid. Ver Lallemand, M.: Des pertes séminales involontaires, Paris-Montpellier, 1836, obra traducida pronto al castellano (LALLEMAND, M.: De las pérdidas seminales involuntarias, Barcelona, Imp. S. Verdaguer, 1838).

62 Descuret, Jean Baptiste F.: La Medicina de las Pasiones, Barcelona, Imp. y Lib. Pablo Riera, $2^{\mathrm{a}}$ ed., 1857, p. 37. Traducida por P. F. Monlau, hubo una primera edición castellana en 1842.

63 MONLAU, Pedro Felipe: Elementos de higiene privada, op. cit., p. 466. 
- Como afirmaba el higienista gaditano Benito Alcina, catedrático de Higiene en la Facultad de Medicina de Cádiz y miembro del grupo de médicos (junto a Santero o Rodríguez Méndez) que, desde los años 80, impulsaron la higiene experimental, estableciendo sus fundamentos en razones físicas, químicas o biológicas, la «buena marcha física y moral» de la mujer debía estar garantizada por una serie de preceptos:

«Una severidad prudente que guíe sus pasos, dedicarse a las faenas de la casa, cultivo intelectual moderado [...], y no consentir en generar amores hasta pasados los dieciocho años» 64 .

Respecto al onanismo, algunos higienistas europeos consideraban que era muy frecuente en las niñas en la primera edad (antes que en los niños), debido fundamentalmente a «la forma de sus partes genitales». Esto último favorecía que, ante cualquier causa irritativa (como la falta de limpieza o las lombrices), la niña frotara o rascara sus genitales, lo que al procurarle «sin duda sensaciones agradables» se convertiría en un hábito pernicioso $0^{65}$. J. B. Fonssagrives, que, como en otras cuestiones, seguía aquí a Deslandes, afirmaba que «los casos de precocidad extrema de los hábitos viciosos que han sido publicados son concernientes todos a niñas», situando en las "causas mórbidas» el origen de esta precocidad. Sin embargo, el onanismo en los niños, aunque más tardío, sería más frecuente; y ello por varias razones: la educación en común (frente a la educación familiar de las niñas), la disposición exterior de sus órganos genitales y «el cultivo prematuro e intenso de la inteligencia» ${ }^{66}$.

En general, en el onanismo femenino, señalaba Francisco J. Santero - catedrático de Higiene en la Facultad de Medicina de Madrid, en la que sucedió a Monlau -, aunque no existía pérdida seminal, "como el sistema nervioso es más impresionable», el exceso de los placeres venéreos venía a producir los mismos resultados, "pues el colapso es más profundo» ${ }^{67}$. Aunque el onanismo femenino aparecía soslayado o pobremente tratado en los manuales de higiene (excepto unos pocos tratados específicos), algunos autores, como el francés Debay, sostenían que «el bello sexo es el que ofrece más frecuentes ejemplos de esta deplorable pasión", debido entre otras causas al «desarrollo del sistema genital de la mujer, que parece dominar el organismo entero, y

64 AlcinA, Benito: Tratado de Higiene Privada y Pública, Cádiz, Lib. José Vides, 1882, tomo I, p. 511.

65 Deslandes, M. L.: Compendio de Higiene Pública y Privada. Tratado elemental de los conocimientos relativos a la salud, y a la perfección física y moral de los hombres, Gerona, A. Oliva (impresor de S.M.), 1829-1830, vol. 1, p. 281. Obra traducida y anotada por D. J. D-L. C. (La edición original francesa era de 1827).

${ }^{66}$ FONSSAGRIVES, Jean Baptiste: Tratado de la Higiene de la infancia, op. cit., p. 456.

${ }^{67}$ SAntero, Francisco J.: Elementos de Higiene Privada y Pública, Madrid, El Cosmos Editorial, 1885, tomo I, p. 411. Esta obra sirvió de manual de estudio al menos hasta 1887. 
luego, como las jóvenes viven más sedentariamente que los hombres, tienen menos ocasiones de distraerse de su funesta pasión» ${ }^{68}$.

La masturbación aparecía como posible causa de dos enfermedades propias de la mujer, la ninfomanía o "furor uterino" y la histeria, que tenían una relación directa con el útero (ese "pequeño déspota» que tiranizaba su constitución). En los tratados médicos de enfermedades de la mujer, la masturbación no aparecía como una actividad sexual específica, sino como causa, síntoma o etapa del «furor uterino». Frente al masturbador tímido y debilitado, la ninfómana caía en el furor y el delirio que representaba su iniciativa erótica ${ }^{69}$.

Se alertaba sobre la aparición precoz de la menstruación en la joven (entre cuyas causas se mencionaba la masturbación), se advertía sobre los peligros de su supresión y se recomendaba tomar precauciones higiénicas e incluso iniciar una instrucción fisiológica que evitara que estas transformaciones en su organismo pudieran sobresaltar su «exquisita sensibilidad»: «Enterar a la niña, por medio de una explicación sencilla de los cambios que van a presentarse en su economía» ${ }^{70}$. Giné y Partagás defendía que era necesario evitar que la mujer «se entregue tempranamente a las funciones de la reproducción», situando la edad del matrimonio a partir de los dieciocho o veinte años, aun cuando la aptitud fisiológica para la procreación se alcance antes y la «nubilidad legal» estuviera situada a partir de los doce años.

Respecto a la variable de la raza, hacia mediados del siglo XIX surgió un racismo científico que empezó a legitimar la inferioridad biológica y antropológica de la raza negra ${ }^{71}$. En las sociedades occidentales se establecieron complejas interacciones entre el prejuicio racial, las diferencias de clase y la jerarquía de género. Se trazaron afinidades entre los salvajes de las colonias, los bárbaros de las metrópolis (las clases trabajadoras) y la tutela de la infancia y la mujer. Aunque en España no se consolidó una fuerte tradición colonial africanista, sí se reprodujeron estereotipos sexo-raciales, que en los tratados de higiene aparecían en las referencias a la influencia de los climas cálidos y las formas de vida promiscua sobre la precocidad sexual de los individuos.

Según Gustau Nerín, el negro se convirtió así en Guinea ecuatorial en «el más impopular de los salvajes». Ni siquiera los defensores ilustrados de la teoría del «buen salvaje» lo defendieron, considerando al indio americano como prototipo del primitivo «bueno»:

\footnotetext{
${ }_{68}$ DeBAy, Auguste: Higiene de los placeres y de los dolores, Barcelona, Felipe N. Curriols, 1892, p. 42. Obra traducida al castellano por el divulgador Amancio Peratoner.

69 VÁzQUEZ García, Francisco: «Ninfomanía y construcción simbólica de la Femineidad (España, siglos XVIII-XIX)", en CANTERLA, Cinta (ed.): VII Encuentro de la Ilustración al Romanticismo. Cádiz, América y Europa ante la Modernidad. La mujer en los siglos XVIII y XIX, Cádiz, Publicaciones de la Universidad de Cádiz, 1994, pp. 125-135; VÁZQUEZ García, Francisco y MORENo MENGíBAR, Andrés: Sexo y Razón, op. cit., pp. 434-435.

70 Giné y PARTAGÁs, Juan: Curso elemental de Higiene Privada y Pública, op. cit., pp. 554-555.

71 Ver PeSET, José Luis: Ciencia y Marginación, Barcelona, Crítica, 1983, pp. 15-78.
} 
«Hasta cierto punto, el negro se convirtió, entonces, en el contrapunto del indio. Si para éste (una vez aniquilado) el europeo le creó una imagen asexuada, pacífica, serena, edénica..., el negro, desde el siglo XVI, se convirtió en el paradigma de la sensualidad y la lujuria brutal» 72 .

Sin embargo, a partir de los años treinta del siglo XX, sectores minoritarios de la escuela colonial española interpretaban la «anarquía sexual» de «nuestros indígenas» como reflejo de un estado adánico, de inocencia o "de naturaleza», fuera de las restricciones culturales ${ }^{73}$.

Aunque en las cartillas de higiene colonial escritas hacia finales del siglo XIX para las últimas colonias españolas (Filipinas, Cuba, Puerto Rico, Fernando Poo) no encontramos referencias explícitas a la sexualidad infantil, ni al onanismo (sólo indirectas alusiones a la influencia del clima en la precocidad de los individuos), estas cartillas son interesantes para entender las conexiones que desde finales del siglo XIX se hicieron entre el salvaje y el niño. En algunos influyentes higienistas, como el francés Descuret, la masturbación se situaba dentro de las "necesidades animales o inferiores», predominantes en la infancia «así del hombre como de los pueblos» ${ }^{4}$.

En el ámbito de la Higiene del matrimonio, el lazo conyugal aparecía con frecuencia como último remedio frente a peligros como el onanismo o la prostitución; peligros que amenazaban especialmente en los casos de celibato prolongado. Frente a la «estéril soledad» del onanista, se contraponía el legítimo «placer compartido» ${ }^{75}$, rechazando los ideales de la continencia y castidad cristianos.

Uno de los manuales sobre Higiene del matrimonio más editados en España durante el siglo XIX, y probablemente el iniciador de este género en nuestro país, fue el del famoso higienista P. F. Monlau ${ }^{76}$. Monlau advertía que su tratado era una «obra filosófica y médica» destinada a la consulta de padres de familia (junto a médicos, matronas y eclesiásticos), frente a otras donde buscaban «inspiración erótica» los jóvenes, lo que indica la ambigua recepción y los distintos usos por parte de los lectores de este tipo de literatura. Su obra contenía «las reglas e instrucciones necesarias para conservar la salud de los esposos, conservar la paz conyugal y educar bien a la familia». Monlau recogía gran parte de las causas físicas y morales que la tradición médica antionanista atribuía al desencadenamiento del onanismo, y proponía el examen microscópico

\footnotetext{
${ }^{72}$ Nerín, Gustau: Guinea Ecuatorial: bistoria en blanco y negro, Barcelona, Península-Atalaya, 1998, p. 62.

${ }_{73}$ Ibid., p. 65.

74 Descuret, Jean Baptiste F.: La Medicina de las Pasiones, op. cit., p. 25.

75 SANTERo, Francisco J.: Elementos de Higiene Privada y Pública, op. cit., tomo I, p. 409.

76 MONLAU, Pedro Felipe: Higiene del Matrimonio o El Libro de los Casados. En el cual se dan las reglas e instrucciones necesarias para conservar la salud de los esposos, asegurar la paz conyugal y educar bien a la familia, Madrid, Imp. M. Rivadeneyra, $2^{a}$ ed., 1858. La primera edición era de 1853 , alcanzando su décima edición en 1898, y la última conocida en 1928. Se editó una versión francesa en París en 1879.
} 
de la orina (en busca de la presencia de oxalato de cal que denunciara la presencia del hábito onanista) como un método «sin riesgo de despertar en el niño ideas que tal vez no tiene ${ }^{77}$. La masturbación era señalada como una de las causas de las disfúnciones que amenazaban a la vida conyugal: la impotencia, la esterilidad y la anafrodisia (o «indiferencia para los placeres del amor» $)^{78}$.

Así, en uno de los textos de higiene del matrimonio más editados en España durante el siglo XIX, el del francés A. Debay ${ }^{79}$, se señalaba a «la masturbación y clitoridismo habituales» como causas de la anafrodisia, pues «las partes gastadas por el roce» habrían "perdido su sensibilidad». También el «vicio solitario» podía ser causa de esterilidad y, especialmente en el hombre, podía producir impotencia temporal (para la cual citaba como remedios la flagelación, la urticación o la electricidad) ${ }^{80}$; en cambio, la impotencia femenina no interesaba a los médicos: no resultaba funcional. En la mujer podría producirse «indiferencia, repulsión, esterilidad, pero no impotencia verdadera» ${ }^{81}$.

En este sentido, en el campo de la medicina legal, el onanismo rara vez dio lugar a prácticas judiciales, por la falta de indicios físicos seguros de la presencia del hábito y porque la impotencia temporal que podía provocar no se consideraba impedimento legal para el matrimonio ${ }^{82}$. No obstante, la sospecha de prácticas onanistas en las víctimas de atentados sexuales sí podía comprometer su inocencia.

En el capítulo dedicado a la educación de los hijos, y dentro de la sección dedicada a la puericia (de los 7 a los 15 años), Monlau reproducía las advertencias del discurso higienista europeo (especialmente de los franceses Descuret y Lévy) contra la masturbación, a la que definía como «especie de enfermedad sin dolor, pero vicio odioso y funesto que trae de seguro la ruina del cuerpo y la perdición del alma» ${ }^{83}$. Monlau citaba al respecto una curiosa técnica de un tal doctor Bernt:

«Aconseja que se despierte de repente a los niños: si son inocentes, se quedan tranquilos; pero en el caso contrario, suelen llevar presurosamente las manos a las

\footnotetext{
77 Ibid., p. 524.

78 Ibid., pp. 522-523.

79 DeBAY, Auguste: Higiene y Fisiología del Matrimonio. Historia natural y médica del bombre y la mujer casados, Madrid, Imp. J. López, 1863. Traducido de la $17^{\text {a }}$ edición francesa por Antonio Blanco y Fernández. Existía una edición anterior, traducida por Gerardo Blanco, y dos posteriores en 1871 y 1892.

80 Ibid., pp. 213-284.

81 MONLAU, Pedro Felipe: Higiene del Matrimonio, op. cit., pp. 167-169.

82 MATA, Pedro: Tratado de Medicina y Cirugía Legal. Teórica y Práctica. Obra premiada por el Gobierno, oído el Consejo de Instrucción Pública, Madrid, Carlos Bailly-Baillière, $5^{\mathrm{a}}$ ed., 1874, tomo I, p. 324. El autor, catedrático de Medicina Legal y Toxicología en la Universidad Central de Madrid, propuso esta obra como libro de texto. Defensor del método experimental, impulsor del positivismo científico, en su segundo exilio en París trabajó con Orfila. En esta obra se defiende de las críticas que la acusaban de «inmoral, antidogmática e impía».
}

${ }^{83}$ MONLAU, Pedro Felipe: Higiene del Matrimonio, op. cit., p. 620.

Hispania, LXIV/3, núm. 218 (2004) 835-868 
partes genitales, si es que no duermen ya teniéndolas puestas sobre tal región, como acostumbra a suceder en los niños dados al vicio que nos ocupa»84.

En los consejos a los padres acerca de los medios de precaver y curar la práctica masturbatoria, Monlau recomendaba una vigilancia inicial donde se conciliara el ejercicio de la autoridad con un «amoroso respeto». Pero, una vez que se despertara precozmente el «instinto erótico», los padres debían buscar las confidencias de sus hijos (apartando la intromisión de otros agentes externos) e iniciar una instrucción «metódica y muy graduada» sobre "algunas sencillas nociones de anatomía y fisiología» que satisfaciera su curiosidad ${ }^{85}$. Aparece aquí un intento precoz de una ilustración científica del sexo dirigida a los jóvenes, que se enfrentaba a la tradicional educación en el pudor y a una instrucción centrada exclusivamente en las advertencias de los peligros de conductas sexuales precoces como el onanismo.

En la higiene de la adolescencia, cuando aparecía la facultad reproductora y se iba entrando en edad casadera, Monlau recomendaba a los padres que, al despedirse sus hijos de la casa paterna, pusieran en sus manos un ejemplar de su libro (Higiene del Matrimonio) «a fin de que puedan conducirse dignamente en su nuevo estado conyugal». Seraine, por su parte, aunque advertía de los graves peligros del onanismo (para lo que se apoyaba en su obra en algunos de los ejemplos de Tissot y Zimmerman), y llegaba a recomendar a los padres poner en manos de los hijos el famoso tratado de Tissot, prefería apelar en última instancia «a los instintos generosos de la juventud». Frente a los peligros del uso prematuro de la «potencia sexual», «la mejor señal de una verdadera energía moral y el más hermoso triunfo consisten en combatir las pasiones y en saber vencerlas»; para ello, los padres debían impeler a sus hijos hacia el «amor moral» ${ }^{86}$.

\section{CONFESORES E HIGIENISTAS}

Desde el higienismo europeo, se denunció con frecuencia los valores de la castidad y continencia cristianos o la exaltación del celibato, y se alertaba de los peligros de la extensión del onanismo en los colegios e internados religiosos. Los higienistas propusieron en ocasiones el recurso de la confesión, pero transformándolo como un remedio terapéutico en manos de padres y médicos, y sólo cuando existían pruebas bien fundadas de la existencia de tales prácticas. Esta estrategia, aun así, despertaba ciertos recelos entre los higienistas: desconfiaban de la eficacia de emplear únicamente remedios morales como la ver-

\footnotetext{
${ }^{84}$ Ibid., p. 623.

85 Ibid., p. 526.

86 SERAINE, Louis: De la salud de los casados. Fisiología de la Generación del Hombre e Higiene Fisiológica del Matrimonio, Traducida por Joaquín Gassó, Madrid, Carlos Bailly-Baillière, 1867 ( $1^{\mathrm{a}}$ ed., 1866), pp. 23-24. Esta obra alcanzó su $5^{\text {a }}$ edición en 1878.
} 
güenza o el arrepentimiento, y temían alertar y activar las defensas del onanista o hacerle sospechar de asuntos que ignoraba. De esta forma, la confesión del vicio fue generalmente desplazada por la conveniencia de una instrucción preventiva y pudorosa acerca de los peligros del onanismo.

En España, el discurso higienista conectó con frecuencia durante el siglo XIX con las tesis liberales y anticlericales: denunció la confesión auricular o romana como un modo de enseñar asuntos que el niño debía ignorar, y advertían del peligro de la solicitación por la influencia del confesor sobre las mujeres ${ }^{87}$. El ilustrado sevillano Blanco White, en sus Cartas de España (1822), denunciaba así los perniciosos efectos de la confesión, y su influencia moral sobre la infancia:

«Sus efectos sobre las almas infantiles no dejan de ser perjudiciales para su futura paz de espíritu y para el desarrollo de las virtudes. A la práctica de la confesión debo yo mis primeros remordimientos cuando todavía mi alma se encontraba en un estado de pureza infantil» 88 .

Blanco White escribió en su exilio inglés la obra The Preservative Against Poppery, donde, como recoge Haliczer, «advierte de los efectos perniciosos de la confesión auricular sobre los niños y las familias y del peligro que representaba para el sexo femenino». Como el sacerdote estaba obligado a indagar en los pecados sexuales para llevar a cabo sus deberes de confesor, «la comunicación sucia es inseparable del confesionario» ${ }^{89}$.

Sin embargo, como veremos a continuación, también se establecieron conexiones y afinidades durante el siglo XIX entre el discurso médico antimasturbatorio y algunos sectores católicos, como se refleja en la obra del influyente teólogo español el Padre Claret. Ya en la edición castellana de la obra de Alfonso de Ligorio El bombre apostólico, pese a que la polución de niños y jóvenes no era estudiada en el análisis de los actos sexuales contra natura, sí aparecía en el apartado titulado "Cuál debe ser la conducta del confesor con los niños y jóvenes de ambos sexos» ${ }^{90}$. El confesor debía desplegar, afirmaba Ligorio, «toda su caridad, y unas maneras cuanto sea posible cariñosas»; debía estimular la confesión de los

\footnotetext{
87 Sobre el peligro de solicitación, ver HALICZER, Stephen: Sexualidad en el confesionario. Un sacramento profanado, Madrid, Siglo XXI, 1998, pp. 255-285.

88. BLANCO White, José: Cartas de España, Madrid, Alianza, 1986, p. 85.

-89 Haliczer, Stephan: Sexualidad en el Confesionario, op. cit., p. 259. Sobre los peligros de la confesión auricular para la moral y la familia, ver también C. W.: El Confesionario. Traducción libre de una obra francesa que no es "La llave de oro», Madrid, 1869. En esta obra se afirma que "se escuchan y aprenden cosas en el confesionario por seguir los preceptos del Manual del Confesor», el cual «revela y excita cosas ignoradas» (p. 54).

${ }^{90}$ LIGORIO, San Alfonso de: El bombre apostólico instruido para el confesionario o sea práctica e instrucción de confesores, Barcelona, 1846, 3 vols. Ver VARELA, Julia y ÁlVAREZ-URÍA, Fernando: «El sexo de los ángeles», en Las redes de la psicología, Madrid, Ed. Libertarias, 1986, pp. 107-110, y, sobre la modulación estilística y retórica de la discreción en la confesión; especialmente de los niños, que se inició con Alfonso de Ligorio, FouCAUl, Michel: Les Anormaux, op. cit., pp. 204-205.
}

Hispania, LXIV/3, núm. 218 (2004) 835-868 
pecados que se acuerden, y después, preguntar «si han callado algún pecado por vergüenza» $\mathrm{y}$ «si han cometido algún pecado torpe» ${ }^{91}$. Ligorio recomendaba cautela, y un largo rodeo, en el interrogatorio sobre estas cuestiones:

«Empieze a hacerlo de lejos y con palabras generales; y primeramente si han dicho malas palabras; si han enredado con otros niños y niñas, y si hicieron aquellos juegos a escondidas. Pregúnteles después si han ejecutado acciones torpes. Muchas veces aunque nieguen los niños es provechoso hacerles preguntas sugestivas, v. g., «Vamos, dime ahora: ¿Cuántas veces has hecho esto? ¿Cinco? ¿Diez?». Pregúnteles con quién duerme y si han enredado en la cama con las manos. A las doncellas pregúntelas, si amaran algún joven, y si tuvieran malos pensamientos, palabras o tactos; y en vista a sus respuestas proceda a ulteriores preguntas. Pero guárdese muy bien de preguntar a los niños de uno u otro sexo an adfuerit seminis effusio; pues con éstos vale más faltar a la integridad material de la confesión, que ser causa de que aprendan lo que no conocen, o de que entren en curiosidad de saberlo»92.

El teólogo Antonio $\mathrm{M}^{\mathrm{a}}$ Claret, quien tuvo gran influencia en la pedagogía española del siglo XIX, interviniendo en los planes de primera y segunda enseñanza de 1868, dejó un poco más clara la intención de estas técnicas de interrogatorio, al proponer ejemplos del «Modo de confesar a un niño que no sabe acusarse por sí. solo, y que necesita que el confesor le pregunte» ${ }^{93}$. Respecto a la confesión de los niños, Claret recogía también, no obstante, ciertas prácticas más laxistas como las del padre Pedro de Calatayud que, defensor de la inocencia y sinceridad de los niños, afirmaba que «sus pecados no suelen ser graves y suelen ser menor que en los grandes: no existe la tiranía de la pasión de los mayores». Bastaba entonces con breves preguntas con que despachar a los niños: «P. ¿Has hecho alguna picardía, o cosa mala con algún otro niño o niña? R. No, padre» ${ }^{94}$. Las recomendaciones de cautela respecto a la dirección de la penitencia de niños y jóvenes fueron frecuentes en los manuales de confesores. El canónigo italiano A. Ciolli recomendaba así una dirección gradual por parte del confesor, con el propósito de «acostumbrarlos a mortificar las pasiones y alejarlos del peligro»"95.

${ }^{91}$ Fr. LÁrRAGA, Francisco: Prontuario de la Teología moral, Barcelona, Imp. Pablo Riera, $4^{\mathrm{a}}$ ed., 1858 , p. 587 . Esta obra, reformada y corregida por $\mathrm{A}$. $\mathrm{M}^{\mathrm{a}}$ Claret, tuvo ocho ediciones durante el siglo XIX. El capítulo dedicado a la práctica del confesor está extractado de El bombre apostólico de Ligorio.

92 Ibid., p. 587.

${ }_{33}$ ClARET, Antonio $\mathrm{M}^{2}$ : Llave de Oro, o Serie de reflexiones que, para abrir el corazón cerrado de los pobres pecadores, ofrece a los confesores nuevos, el Ilmo. Sr. D. A. Ma Claret, Barcelona, Librería Religiosa, 1860 , p. 138.

${ }_{94}$ ClARET, Antonio $\mathrm{M}^{\mathrm{a}}$ : Nuevo Manojito de Flores. Recopilación de doctrinas para los confesores, Barcelona, Librería Religiosa, 1859.

95 Ciolli, Antonio: Directorio práctico del confesor, Traducido de la $5^{\text {a }}$ edición italiana por el Rdo. Cayetano Soler, Barcelona, Juan Gili, 1901, pp. 324-325. 
Claret, arzobispo de Cuba, pedagogo, confesor de Isabel II y preceptor de sus hijos, llegaba a afinar todavía más en las tácticas indirectas de interrogatorio en el apartado referido al «Modo de comportarse el confesor con los tocados por este vicio (molicie), mayormente si son mujeres». Si la polución femenina apenas había interesado en la anterior consideración cristiana de la molicie, durante el siglo XIX, tanto desde la confesión como desde la teología moral, el onanismo femenino ocupó un papel destacado. A este respecto, Claret advertía cómo, según su práctica y experiencia, «las niñas son más fáciles de cometer impureza que los niños, mientras son pequeñitas», aunque cuando son mayores —indicaba- «va enteramente al revés»; y ello debido a su misma naturaleza y a sus juegos «a padres y madres» $\$ 6$.

Citando al teólogo francés Debreyne y al higienista Deslandes, Claret insistía en que «este vicio hace tantas o más víctimas entre las mujeres que entre los hombres. En algunas empieza desde la cuna» ${ }^{97}$. Las niñas eran atraídas hacia este «vicio abominable» por una «especie de instinto» que unido a su fuerte «sensibilidad amativa», conducía a más funestos resultados que en los hombres: «afecta más a su sensibilidad y ataca más a su sistema nervioso» ${ }^{98}$. Claret recomendaba a madres y maestras "vigilar mucho», "pues entre niñas y muchachas suceden cosas que hacen estremecer": Aquí, la castidad femenina se configuraba como un modelo de virtud, contrapunto en ocasiones del modelo de dama frívola, reflejo de la autonomía de las mujeres de las élites en la sociedad cortesana. La crítica a la dama aristocrática, a su ociosidad y «vida muelle», iría en la línea de potenciar el papel de la mujer en la esfera de la reproducción y la maternidad 99 .

Claret advertía al sacerdote que no debía dar a entender curiosidad ni admiración ante la confesión de estas «acciones torpes»:

«Antes bien le puede decir que no le dirá ninguna cosa nueva, porque en los libros todo se halla, y que él sabe mucho más de lo que ella le puede decir. Esto las anima mucho» 100 .

En la confesión, además, se acechaba y provocaba la auto-delación, se tendían trampas cada vez más refinadas para desenmascarar al onanista y a sus cómplices:

96 Claret, Antonio $\mathrm{M}^{\mathrm{a}}$ : Llave de Oro, op. cit., p. 138.

97 lbid., p. 81.

98 Ibid., pp. 82-125.

99 Como ejemplo de esta crítica, ver Coloma, Padre Luis: Pequeñeces, Bilbao, El Mensajero del Corazón de Jesús, 4 vols., 1891. Esta novela costumbrista describía la vida y andanzas de la «disoluta» condesa Currita Albornoz, con lo que pretendía criticar los modos de vida de una aristocracia decadente.

100 LÁrraga, Francisco, Prontuario de la Teología Moral, op. cit., p. 687. Esta obra incluye, junto al extracto de la obra de Ligorio, la Llave de Oro de A. $\mathrm{M}^{\mathrm{a}}$ Claret.

Hispania, LXIV/3, núm. 218 (2004) 835-868 
«Le preguntará ¿cuántas veces lo ha cometido? [...] Si se para en responder, y que, con la sorpresa en que se halla, ya da a entender que lo cometió, le propondrá un número mayor del que piensa que haya cometido, y así, creyéndose descubierta le confesará ella el número cierto. Antes de que ella acabe de explicar el número y su gravedad, como si el confesor la quisiera excusar, le dirá: Seguramente Vd. no habría hecho esto si no hubiera sido inducida por otra persona; y con la respuesta que dé se conocerá si ha habido complicidad»101.

Claret seguía en gran parte la línea higienista antimasturbatoria, citando con profusión a autores como Descuret, Deslandes, Tissot o Franck. En este sentido, en el apartado dedicado al sexto mandamiento, y en referencia a la mollities, señalaba cómo, "conforme a los principios de la medicina», ésta ocasionaba la enfermedad del vicioso (estrujando su naturaleza «como una naranja»); provocando, además, daños en «las potencias del alma» (en el entendimiento, la memoria o la voluntad), y sin olvidar los tormentos religiosos y la condena "a la cárcel del infierno»" ${ }^{102}$.

Entre los remedios «contra la impureza», repetía gran parte de las propuestas higiénicas (cama dura, baños frescos, alimentación ligera, «camisolas de mangas cerradas y atadas al cuello» o «dormir del lado derecho»), pero añadía una larga lista de remedios morales: «firme resolución de no pecar más», «apartarse de personas, cosas y lugares que inducen a pecar», «apartar el pensamiento de estas cosas», "pensar que Dios está mirando», «fijar los ojos de la consideración en el Calvario y en las penas del infierno", "frecuencia de los Santos Sacramentos», "oración mental y lectura espiritual» y "devoción a María Santísima»103.

Claret añadía algunos «remedios físicos de segunda clase» como la magnesia, las preparaciones ferruginosas, agua de cal, etc. Asimismo incorporaba algunas reflexiones a los onanistas adultos en las que intentaba vencer sus argumentos, dando respuesta a «excusas» como la de practicar el onanismo conyugal para no tener hijos, por los padecimientos del parto o, en la mujer, por imposición del marido: "yo no quisiera, pero él lo quiere así» ${ }^{104}$. En sus textos, Claret señalaba a la madre como «primera educadora», y defendía la educación familiar como freno de la «corrupción social moderna». El ejemplo y la vigilancia debían apartar a los niños de los peligros que amenazaban su castidad y de las malas compañías. Los padres, advertía Claret, debían apartar a los hijos de sus camas lo más tardar a los cuatro o cinco años, y desconfiar de que estos permanecieran despiertos en la cama, fingiéndose dormidos.

\footnotetext{
101 Ibid., p. 687.

102 ClareT, Antonio $\mathrm{M}^{\mathrm{a}}$ : Llave de Oro, op. cit., p. 77.

103 LÁrraga, Francisco, Prontuario de la Teología Moral, op. cit., p. 688.

${ }^{104}$ Sobre la producción pedagógica de Claret, ver ClARET, Antonio $\mathrm{M}^{\mathrm{a}}$ : La Educación de los hijos, Búsqueda, ordenación y comentarios del R. P. Jaime M. Torras, Madrid, 1953.
} 
Por otro lado, en el famoso Catecismo del Padre Astete, de larga vida durante el siglo XIX y en el que se instruyeron muchas generaciones jóvenes, se afirmaba también en la lección sobre el sexto mandamiento:

«¿Quiénes pecan? Los que advertidamente se deleitan en pensamientos impuros, aunque no los pongan ni deseen poner en obra, los que hablan y cantan cosas torpes o con complacencia los oyen, y los que consigo mismos, o con otros, tienen tocamientos deshonestos o los desean ejecutar»105.

Entre los medios que proponía este catecismo para conservar la castidad figuraban «el recato en el trato familiar y conversaciones con personas de otro sexo", «la mortificación del cuerpo y guarda de los sentidos», la «humildad profunda» y la "oración continua y fervorosa». En esta lucha por la castidad y contra la impureza, se dedicaban apartados especiales a aspectos como los bailes y los libros prohibidos. Respecto a los primeros, ante el peligro de que pudieran despertar las pasiones o incentivar la sensualidad o la lujuria, sólo se aceptaban «cuando se guardan rigurosamente las leyes de la honestidad, excluyendo todas las acciones, movimientos, vestidos y ademanes indecorosos, libres o menos decentes» ${ }^{106}$. Respecto a las novelas, a la vez que prohibía las inmorales e impías, consideraba que «las demás no hacen provecho»:

«Porque excitan la imaginación y las pasiones, resfrían el sentimiento religioso, debilitan la autoridad y los vínculos de familia y hacen enojosa y pesada la vida práctica por el deseo de realizar la vida ideal que pintan»107.

Esta lucha por la castidad y la educación en la pureza tuvo, más tarde, un fuerte impulso dentro de la pedagogía católica de principios del siglo XX, con representantes tan destacados como el jesuita Ruiz Amado o el Padre Manjón, que intentaron dar respuesta alternativa a los primeros intentos de instrucción sexual.

\section{HIGIENISTAS Y PEDAGOGOS. ¿EDUCACIÓN DOMÉSTICA O COMÚN?}

El discurso médico-higienista del siglo XIX había dirigido principalmente sus esfuerzos al ámbito de la enseñanza doméstica, lugar natural de la educación para la clase burguesa, frente al abandono de una enseñanza, la primaria,

10s Rvdo. Padre Astete, Gaspar: Religión y Moral. Catecismo, Texto adicionado y explicado por el Dr. D. Bernardo S. Casanueva, Canónigo de la Santa Iglesia Catedral de esta Corte, Rector del Seminario Conciliar y Profesor de esta asignatura en la Escuela Normal Central de Maestras. Obra destinada a niños de catequesis, jóvenes alumnos de colegios católicos, Escuelas dominicales y Círculos de obreros, Madrid, Imp. Vda e Hijo de Aguado, 1887, p. 96.

106 Ibid.

107 Ibid., p. 70.

Hispania, LXIV/3, núm. 218 (2004) 835-868 
marcada por el carácter y destino social de sus receptores: los hijos de las clases populares. P. F. Monlau, defensor de la introducción de la higiene en la enseñanza, criticaba como peligrosa una instrucción prematura que forzaría el desarrollo de las facultades intelectuales, descuidando las prioritarias en los primeros años: las físicas y afectivas ${ }^{108}$. En la puericia, entre los siete y quince años, donde, además del gimnasio, el niño debía empezar a frecuentar la escuela, era donde empezaría el cultivo de las facultades intelectuales tras una «escrupulosa elección de maestros y maestras».

Desde el higienismo, se criticaba a los padres que abandonaban a sus hijos en «manos extrañas», y sólo cuando el niño, en la edad de la pubertad, debía entrar en el colegio, recomendaban escoger a sus maestros con mucho cuidado, advirtiendo a los padres de la necesidad de instruir a sus hijos, para preservarles de los posibles contagios morales que entrañaba la convivencia de los jóvenes en un espacio de difícil vigilancia y atención. En las últimas décadas del siglo XIX, esta crítica de la educación "pública» se hizo todavía más intensa desde el higienismo, fundamentalmente desde el ámbito católico. Estos sectores continuaban defendiendo la educación doméstica o de los colegios religiosos y criticando los valores (o a la ausencia de «verdaderos valores») de la educación lai$\mathrm{Ca}^{109}$. Encontramos incluso las primeras referencias directas a la presencia de la pederastia en la escuela ${ }^{110}$.

En general, los higienistas, a pesar de que solían recomendar el fortalecimiento de la educación moral y religiosa dentro de su arsenal terapéutico, desconfiaban de su aplicación en la escuela pública: allí no se podía ejercer una vigilancia continua y próxima. Sólo desde una mirada que se solicitaba hacia el interior de la familia, frente a la sociabilidad externa, se haría eficaz ese control.

No obstante, dentro del higienismo hubo tempranas excepciones, como el tratado del francés Dr. Simon, «dedicado a la juventud reunida en las casas de educación", y traducido pronto al castellano ${ }^{111}$. En él sostenía, contra muchos higienistas de su época, las ventajas de la vida en los colegios frente a la educación doméstica. Aunque reconocía como «incontestable» el hecho de que «la masturbación existe en todas las reuniones de jóvenes», y señalaba el peligro de la «incitación de amigos y maestros», también afirmaba que el colegio permitía libertad de movimientos y preservaba al joven de los peligros del «mundo», de la sociabilidad pública adulta:

${ }_{108}$ Monlau, Pedro Felipe: Elementos de Higiene Privada, op. cit., p. 475. Monlau publicó en 1840 un ensayo sobre la instrucción pública en Francia (MONLAU, Pedro Felipe: De la instrucción pública en Francia, Barcelona, Imp. A. Bergner y Cía., 1840).

${ }_{109}$ FONSSAGRIVES, Jean Baptiste: Tratado de la Higiene de la Infancia, op. cit., p. 454; SANTERO, Francisco J.: Elementos de Higiene Privada y Pública, op. cit., tomo 1, p. 410.

110 Alcina, Benito: Tratado de Higiene Privada y Pública, op. cit., vol. 2, p. 513.

111 Dr. SimON: Tratado de Higiene aplicado a la educación de la juventud, 3 vols., Paris, H. Séguin, 1828.

Hispania, LXIV/3, núm. 218 (2004) 835-868 
«En los colegios no encuentra el joven las numerosas causas que en el mundo electrizan su imaginación, como las sociedades, tertulias, fiestas [...], bailes, teatros y espectáculos en que se mezclan sexos y edades» 112 .

El Dr. Simon, precursor de la aplicación de la higiene a la educación (en especial la educación física), recomendaba una presencia más directa del médico en los colegios y seminarios. Defendía que el médico instruyera «circunstancialmente al joven sobre las funestas consecuencias de esta pasión y ventajas de la continencia», añadiendo que sería "tan útil como agradable un curso en que se diesen ideas generales sobre anatomía, fisiología e higiene» ${ }^{113}$.

A diferencia de este discurso higienista mayoritario, desde la Pedagogía se intentó disminuir la separación entre la educación doméstica y la pública: muchos tratados de pedagogía incluían generalmente entre sus destinatarios a los padres, y la educación pública adoptó, bajo el influjo pestalozziano, también un sistema paternal ${ }^{114}$.

Los pedagogos se habían enfrentado desde mediados del siglo pasado a la idea de gran parte del discurso higienista que atribuía a la educación pública, frente a la doméstica, la pérdida de la inocencia infantil, un foco de contagio del denominado «vicio escolar» (el onanismo). A estos planteamientos se objetaba que, aun existiendo este peligro en los Colegios, muchas veces era desde las casas donde se traía el desorden a las escuelas:

«[...] Son muy pocos los jóvenes que están exentos de este vicio. Los padres conocen rara vez bajo este aspecto a sus hijos; creen que se corrompen en la escuela, y la mayor parte llegan a ella corrompidos, aunque los padres los declaren inocentes. En las buenas casas de educación pueden observarse y corregirse mejor estas cosas que no en el seno de la familia»115.

Higienistas y pedagogos se dirigían a públicos distintos: el recelo de estos últimos hacia la educación doméstica reside en que su referencia son las familias de las clases populares, no la de las élites urbanas. El peligro de «contagio» no provenía muchas veces de la escuela, sino de esas familias populares, donde la falta de atención o la existencia de un ambiente promiscuo, producía el

112 Ibid., vol. II, p. 13.

113 Ibid., vol. II, p. 33.

114 ReNDU, Alphonse: Curso de Pedagogía, o Principios de Educación Pública para uso de las Escuelas Normales y de los Maestros, Tarragona, Imp. A. Puigrubí, 1845, p. 19. Traducido de la segunda edición francesa por M. Carderera, que, junto con J. Avendaño, fue discípulo de P. Montesino y uno de los más influyentes pedagogos normalistas en España. En la introducción a su traducción del texto de A. Rendu, aprobado oficialmente en 1852, Carderera seguía lamentándose de la escasez de obras en español sobre ciencia pedagógica de aplicación a los maestros. Para suplir esta deficiencia, Carderera tradujo esta obra, texto oficial en las Normales francesas.

115 Carderera, Manuel: Diccionario de Educación y Métodos de Enseñanza, Madrid, Imp. R. Campuzano, 1858, vol. IV, p. 420.

Hispania, LXIV/3, núm. 218 (2004) 835-868 
abandono moral de sus hijos. Descreídos respecto al cuidado de la educación moral en el entorno doméstico, y conscientes del peligro de contagio y de la inutilidad de los mecanismos disciplinarios de vigilancia, los pedagogos fueron pronto conscientes de la conveniencia de prevenir instrucciones extraviadas y de los peligros de la estrategia del silencio.

El impulso del saber pedagógico dentro de las prácticas escolares se inició en España con el establecimiento de las Escuelas Normales de maestros, a partir de 1839, aunque su existencia fue precaria debido a un oscilante interés político y una ineficaz legislación que pretendió institucionalizar un sistema público nacional capaz de enfrentarse a las resistencias que oponían las formas de educación gremiales, populares o religiosas existentes.

La Escuela Normal Central de Madrid logró inaugurarse, tras muchas vicisitudes, el 8 de marzo de 1839, para luego extenderse por provincias. Nació con un fuerte carácter centralista e intervencionista por parte del Estado. El Gobierno nombraba al director y profesores, y fijaba las condiciones de admisión de los alumnos ${ }^{116}$. La Pedagogía española, como saber específico, sólo adquirió verdadera importancia a comienzos del siglo XX. Durante el siglo XIX, junto al retraso y falta de recursos de la instrucción primaria, hay numerosos testimonios de la deficiente formación, y no sólo pedagógica, de sus maestros. Sin embargo, frente a esta superficial formación intelectual, la ley sí era exigente respecto a la buena conducta moral del profesorado. Sólo con el agravamiento, durante la Restauración, de la cuestión social y la cuestión femenina, las élites dominantes se interesaron por las posibilidades moralizadoras y de control social de un aparato de educación pública construido, especialmente en la enseñanza primaria, para abarcar a la infancia de las clases populares.

El saber pedagógico que se desarrolló, durante el siglo XIX, en las Escuelas Normales para la formación del profesorado, adoptó aspectos de las principales corrientes pedagógicas europeas desde un fuerte filtro moral y religioso. Dentro de la pedagogía normalista española del XIX, los sistemas de educación modernos (Locke, Rousseau y Basedow) fueron criticados por su carácter de «incompletos», por la falta del componente moral-religioso en la educación ${ }^{117}$.

A su vez, respecto a la moral sexual infantil, recogió parte de las recomendaciones de la tradición higienista sobre la lucha antimasturbatoria, aunque con cierta desconfianza, en sus inicios, sobre la intromisión del médico en la escuela, y sin abandonar el recurso al sacerdote y al remedio religioso. Bajo un lenguaje de

116 MELCón, Julia: La formación del profesorado en España (1837-1914), Madrid, M.E.C., 1992.

117 VEGA GIL, Leoncio: «Las corrientes pedagógicas europeas a la luz del movimiento normalista español del XIX», Historia de la Educación (Salamanca), $\mathrm{n}^{\circ} 4$ (1985), p. 128. Sobre la recepción de la pedagogía normalista europea, se pueden consultar las distintas entradas de autores en el Diccionario de M. Carderera. Como ha señalado Leoncio Vega, en la pedagogía normalista española se mantuvo una postura ecléctica en la que predomina la influencia del movimiento normalista francés (De Gerando, Rendú, Matter y Jacotot), pero que también recoge aportaciones de la escuela suiza (Pestalozzi y Gauthey), anglosajona (Locke, Lancaster y Bell, Dunn, y Horner), y alemana (Basedow, Froebel, Niémeyer). 
sobreentendidos que oculta en muchas ocasiones la supuesta amenaza onanista bajo las denominaciones del mal y el vicio, se insistía en una educación preventiva en el sentimiento del pudor y en la conservación de la pureza de la infancia. En las escuelas, especialmente en los internados, los maestros debían extremar las precauciones y la vigilancia para prevenir la aparición del vicio moral, pues un solo caso bastaba para extender el contagio. Este caso se señalaba como la única ocasión en que era necesario expulsar a un niño de la escuela. Se insistía en vigilar a los niños retraídos o taciturnos, y su trato, conversaciones y juegos con los demás niños:

«[El maestro deberá] castigar severamente a los que se permitan conversaciones indecentes; [...] descubrir los libros o estampas obscenas que pudieran introducirse en la escuela; las romperá al momento en presencia de todos, e impondrá un riguroso castigo al que las haya llevado» 118 .

La educación moral, o en ocasiones la educación física, constituyen los apartados de estos tratados pedagógicos donde se intenta configurar esa moral sexual. El pudor era un sentimiento que ocultaba y velaba ciertas partes o funciones del cuerpo a las miradas de los demás (e incluso de las propias), pero que a su vez «mostraba» y configuraba la imagen del «cuerpo decente». Un cuerpo que, a través de una serie de códigos, signos y manifestaciones, había intentado transformar su superficie en reflejo del triunfo de la voluntad sobre las pasiones ${ }^{11}$.

Las referencias directas a la literatura higienista antionanista son muy escasas, casi inexistentes. Así, la obra de Tissot aparece contadas veces, como en el artículo dedicado al onanismo en el Diccionario de Carderera (que recoge un texto del pedagogo belga Souvet) ${ }^{120}$. Al hablar de la responsabilidad de los directores de escuelas y colegios, este texto de Souvet cita a autores como Tissot, Georget, Debreyne, Descuret y Deslandes. El autor, frente a la práctica de colegios y seminarios belgas, defendía la propuesta higienista de acostarse varias horas después de haber cenado y tras un largo rato de descanso "para prevenir la agitación en los niños, el desvelarse y la excitación de los vicios secretos».

También aparecen referencias a Tissot en el ensayo del pedagogo francés M. Antonio Jullien, declarado oficialmente útil en 1845 para la instrucción primaria y secundaria en España ${ }^{121}$. Marco Antonio Jullien era un pedagogo francés amigo de Pestalozzi, e influenciado por las doctrinas de Locke, Condillac y, con más reservas, Rousseau. En su Ensayo incluye un plan de educación práctica que insiste en un tema reiterado en otros libros: el empleo del tiempo,

\footnotetext{
118 ReNDU, Alphonse: Curso de Pedagogía, op. cit., p. 120.

119 Varela, Julia: «El cuerpo de la infancia», en Sociedad, cultura y educación. Homenaje a la memoria de Carlos Lerena Alesón, Madrid, Centro de Investigación y Documentación Educativa. Universidad Complutense de Madrid, 1991, p. 235.

120 CARDERERA, Manuel: Diccionario, op. cit., vol. 4, p. 134.

121 JULLIEN DE PARIS, M. A.: Compendio del Ensayo General de Educación física, moral e intelectual, Valencia, Imp. I. Ferrer de Orga, 1840, p. 66. Existe una $2^{\mathrm{a}}$ edición de 1845 (Valencia, Imp. Jose Mateu Cervera).
} 
el «biómetro o relox moral». En su decimononocuadro, y en relación con la educación física de los 12 ó 15 a los veinte años, Jullien advierte a padres y preceptores sobre el peligro del onanismo.

No obstante, abundan algunas de las clásicas medidas higiénicas de prevención y tratamiento: fortalecimiento del cuerpo a través de paseos frecuentes, baños fríos, alimentos ligeros, etc.; aunque no se encuentran menciones al uso de remedios y recetas terapéuticas (como el uso de anafrodisíacos), tan abundantes en los textos higienistas.

Lentamente, se abrieron paso los primeros intentos de una instrucción a partir de la pubertad en nociones de higiene o anatomía y fisiología humana. Una instrucción que, no obstante, se proponía individualizada y prudente, orientada más a calmar una curiosidad peligrosa o una conducta desviada que a proporcionar informaciones que se consideraban innecesarias y que amenazaban despertar «la precocidad del instinto». La cuidadosa periodización y la prudencia de esta instrucción preventiva, en la que no se abandonaba en muchas ocasiones el recurso a las viejas técnicas atemorizadoras, pareció abandonada al consejo y experiencia de personas o compañías virtuosas. Sólo más tarde, en el último cuarto del siglo XIX, cuando parecen diluirse las referencias a la amenaza masturbatoria en otro tipo de «anormalidades sexuales», se abrirá paso la necesidad de una instrucción "científica» en la que tomarán creciente importancia las técnicas de gobierno de corte psicológico.

Pedagogía e higiene establecieron también sus alianzas. Ya a mediados de siglo, se recogía esta preocupación por el «contagio» del «vicio escolar» en algunos artículos de revistas médicas. En alguno de ello se contenían propuestas sobre el examen y posterior registro de la desnudez de los niños en la escuela, en la búsqueda de supuestos signos que denunciaban el onanismo y sus abusos. No obstante, el verdadero efecto de tales observaciones, más que en el descubrimiento de síntomas físicos siempre dudosos, parecía residir en descubrir la «timidez y pudor extremos» del masturbador y su temor a ser descubierto. Esta era la verdadera señal de su estigma ${ }^{122}$.

Pero fue a finales de siglo cuando médicos y pedagogos fijaron más claramente sus alianzas y conflictos en torno al problema de la bigiene escolar. Aquí se emplazó el debate sobre el «auxilio» o «intromisión», según la perspectiva, del médico en los colegios; con el establecimiento de la inspección médicohigiénica en la escuela. En el conflicto entre médicos y pedagogos, Pedro de Alcántara García, representante destacado de la pedagogía positivista y profesor normalista de pedagogía, advertía sobre la necesidad de evitar la dictadura del médico o higienista en los dominios de la Pedagogía, deslindando claramente sus esferas de acción ${ }^{123}$. Los facultativos parecían pues haber conquistado, aunque sólo fuera provisionalmente, el último reducto de los pedagogos.

\footnotetext{
122 Dr. DemeauX: «Nuevo método para evitar el onanismo y reprimir sus abusos», op. cit.

123 AlcánTara García, Pedro: Tratado de bigiene escolar, Madrid, 1886, pp. 17-20.
} 